\title{
The effects of heat treatment on very high cycle fatigue behavior in hot-rolled WE43 magnesium
}

Jacob F. Adams, John E. Allison, J. Wayne Jones

Department of Materials Science and Engineering, University of Michigan

\section{Abstract}

The role of crack initiation and short crack growth on fatigue life in the very high cycle fatigue regime (VHCF) is investigated for three heat treatments of the wrought magnesium alloy WE43. As-received (T5) WE43 with a relatively fine grain size was solution treated and aged to produce precipitation strengthened coarse-grained microstructures in the underaged and peak-aged (T6) conditions. Ultrasonic axial fatigue tests with a cyclic frequency of $20 \mathrm{kHz}$ were conducted using smooth specimens. Heat treatment was shown to have a strong effect on fatigue strength, with the fine-grained, strain-hardened T5 condition exhibiting much higher values than the coarse-grained conditions. No significant difference in fatigue strength was observed between the underaged and peak-aged microstructures of equivalent grain size. Crack initiation and short crack growth behaviors in each condition were investigated to determine if one of these behaviors dominated the VHCF lives. It was found that average short crack growth rates for the three conditions were similar and had no clear dependence on microstructural condition. Crack initiation was shown to occur through cyclic slip deformation in particularly large and favorably oriented grains in each condition. Subsurface crack initiation was observed at low stresses and high lifetimes in the coarse-grained conditions, but not in the fine grained T5 condition. Crack growth rates in vacuum were investigated using a unique combination of ultrasonic fatigue instrumentation and scanning electron microscopy (UFSEM) in order to simulate subsurface crack propagation. Environment was shown to have a significant effect on crack growth rate, with rates in vacuum nearly two orders of magnitude lower than in laboratory air.

Keywords: Magnesium, Ultrasonic fatigue, Fatigue crack growth, Fatigue crack initiation

\section{Introduction}

Magnesium alloys are increasingly being considered in structural applications due to their excellent properties, such as low density and high specific strength. These lightweight alloys are particularly attractive in applications where reductions in weight can result in significant improvements to fuel efficiency [1]. However, the fatigue behavior in magnesium alloys has not been investigated as fully as in other structural alloy systems, and the roles of microstructure on fatigue mechanisms are not yet well understood, especially in the VHCF regime, where local microstructure controls crack initiation and early propagation behavior. Ultrasonic fatigue provides a practical method for the study of fatigue behavior in the VHCF regime, and therefore provides a method for the investigation of fatigue mechanisms on the microstructural scale. Progress in the 
use of the ultrasonic technique for understanding fatigue behavior has been reviewed by Bathias [2], Stanzl-Tschegg [3], and Mayer [4].

The fatigue response of an alloy is comprised of different behavioral regimes, including crack initiation, short crack growth, and long crack growth behaviors, which together determine the total fatigue life of a structure. Fatigue life in the VHCF regime is dominated by crack initiation and microstructurally small crack growth, and variation in these behaviors can have a significant effect on total component lifetime [5]. Even at nominally elastic strain levels, cyclic damage can accumulate and lead to crack initiation and failure beyond the HCF regime, i.e., $10^{7}$ cycles, which is often considered a fatigue limit for many non-ferrous materials [6-8]. For magnesium alloys in general, fatigue lifetime data beyond $10^{7}$ cycles is sparse. Ultrasonic testing methods allow for the investigation of fatigue behavior in the VHCF regime much more rapidly than is possible with conventional servo-hydraulic testing methods.

When the crack length is on the order of the microstructural length scale, accurate prediction of fatigue life requires an understanding of the micro-scale mechanistic responses to cyclic stress during initiation and small scale crack growth. Furthermore, crack initiation mechanisms are dependent on fatigue regime, with different initiation mechanisms and their microstructural dependences operating in low cycle fatigue and in the VHCF regime. In the VHCF regime, it has been suggested that, while the strain level is too low to develop persistent slip bands (PSBs), a small fraction of grains exhibit microstructurally irreversible slip [8]. This irreversible slip then accumulates at favorable microstructural locations at the surface, resulting in localized surface roughening and eventual crack initiation [9]. As strain accumulates more rapidly at specific microstructural configurations or features, these mechanisms and microstructural features must be studied in order to understand initiation behavior in magnesium alloys. In the VHCF regime, researchers have observed a variety of crack initiation mechanisms. Studies have shown in a range of alloys that stress-life (S-N) plots exhibit two distinct regions with two apparent asymptotes, an apparent HCF fatigue limit at moderate stresses and a VHCF fatigue limit at lower stresses. These distinct regions occur as a result of a competition between two failure modes, with one failure mode active at lower lifetimes, and a second failure mode creating a secondary fatigue limit at higher lifetimes [10-13]. In a study of fatigue in high strength low alloy steels, Wang et al. observed that failures in the gigacycle regime were dominated by subsurface crack initiation at inclusions, while failures below $10^{7}$ cycles were dominated by surface initiation [12]. Similar results in a beta titanium alloy were observed by Chandran and Jha, who further linked the variation in fatigue life to environmental effects accelerating crack initiation and growth at surface initiation sites [13]. In materials where inclusions or pores do not cause initiation, initiation tends to occur at microstructural sites where the accumulation of irreversible slip is favored. Szczepanski et al. observed crack initiation in Ti-6246 at surface locations featuring larger than average primary alpha, $\alpha_{\mathrm{p}}$, 2 
grains, which occurred by cyclic strain localization on basal and prismatic planes [14]. Fractography of crack initiation sites revealed the presence of many facets with orientations favorable for slip. Huang et al. found that in gigacycle fatigue of a bearing steel, subsurface crack initiation occurred at large, single grains [15]. They further observed that, for subsurface initiation sites, $90 \%$ of the total lifetime was devoted to initiation of the crack. In a study of VHCF of polycrystalline copper, Stanzl-Tschegg and Schönbauer observed strain localization and PSB formation below the conventional "PSB threshold" along with the formation of numerous non-propagating small cracks [16]. They observed that an approximate $100 \%$ increase in strain amplitude was necessary for the formation of a propagating crack, indicating that sub-PSB threshold crack growth may not be possible in some materials.

Many studies of crack initiation in magnesium alloys have focused on the low and high cycle fatigue regimes, and information on crack initiation mechanisms in the VHCF regime is generally lacking. In a study of very high cycle fatigue of extruded AZ80, Shiozawa et al. observed crack initiation along twin boundaries [17]. Fractographic analysis of the initiation site revealed facet-like regions oriented favorably for slip. Xu et al. observed both surface and near-surface initiation during VHCF of a Mg-Zn-Y-Zr alloy [18]. Oxide films were present at each initiation site, but absent elsewhere on the fracture surface. In the high cycle fatigue regime, observed crack initiation mechanisms include cyclic slip deformation active near grain boundaries and in grain interiors [5,19], and at twin boundaries [20], as well as stress concentration around inclusions in many cases[21-25]. In low cycle fatigue, researchers have found crack initiation modes to be dependent on the magnitude of cyclic loading, with cracks initiating both along grain boundaries and at twin tips [26].

Microstructure continues to play a critical role in fatigue behavior as a crack transitions from initiation to short crack growth. During microstructurally short crack growth, interactions between microstructure and the propagating crack can be influential in determining crack growth behavior. Short crack growth behaviors in magnesium alloys have been shown to be strongly affected by microstructural features, including precipitates or inclusions [27], grain size variation [28], and texture $[29,30]$. Furthermore, with the limited number of deformation systems active at room temperature, crack propagation in magnesium alloys has been observed to occur both transgranularly along specific crystallographic planes $[31,32]$ and intergranularly [27,33]. With the growing interest in magnesium alloys, studies of fatigue in wrought magnesium alloys are increasing, but the number of alloy systems that have been studied are limited and fatigue responses vary widely across different alloy systems.

In the present study, fatigue lifetimes (S-N response), microstructurally small crack growth, and fatigue crack initiation behavior of commercial hot-rolled WE43 magnesium alloy are examined using ultrasonic fatigue testing techniques and 
scanning microscopy. The VCHF behavior in three microstructural conditions of the alloy was investigated and discussed in terms of short crack growth behavior and crack initiation mechanisms.

\section{Materials and Methods}

\subsection{Material}

Magnesium alloy WE43 was prepared by Magnesium Elektron Ltd. The alloy was provided as hot-rolled plate in the T5 condition. The composition (wt \%) of the alloy is $3.74 \mathrm{Y}, 2.10 \mathrm{Nd}, 0.52 \mathrm{Gd}, 0.45 \mathrm{Zr}, 0.016 \mathrm{Zn}$, and $\mathrm{Mg}$ (balance). WE43 is primarily strengthened through the development of rare-earth-containing precipitates. The as-received material had been hot rolled and then aged for 48 hours at $204^{\circ} \mathrm{C}$, a condition that is referred to in this paper as T5. Further heat treatment was conducted in our laboratory to produce underaged and peak-aged (T6) microstructures. Solution treatment of the asreceived alloy was conducted at $525^{\circ} \mathrm{C}$ for 8 hours. Aging at $250^{\circ} \mathrm{C}$ for 4 hours and 16 hours was used to produced the underaged and peak-aged conditions. Grain size was measured by standard methods using electron backscatter diffraction (EBSD) mapping (Figure 1) in a Tescan Mira3 scanning electron microscope (SEM) along with EDAX OIM Data Analysis software. The $525^{\circ} \mathrm{C} / 8 \mathrm{~h}$ solution treatment increased the average grain size from $13 \mu \mathrm{m}$ to approximately $113 \mu \mathrm{m}$, as detailed in Table 1. In each condition, fine $\beta^{\prime}$ precipitates are present in the matrix, while coarser $\beta_{1}$ and $\beta_{1} / \beta$ precipitates are found respectively in the underaged and T6 conditions as plate-like structures along prismatic planes [34]. An investigation of tensile behavior in WE43 performed by Githens revealed notable differences in the mechanical properties of the three conditions (Table 1), with the T5 condition exhibiting yield and tensile strengths significantly higher than those of either the underaged or $\mathrm{T} 6$ conditions [35]. In these tests, the tensile loading direction was parallel to the rolling direction, which was the same orientation used in all fatigue tests. 

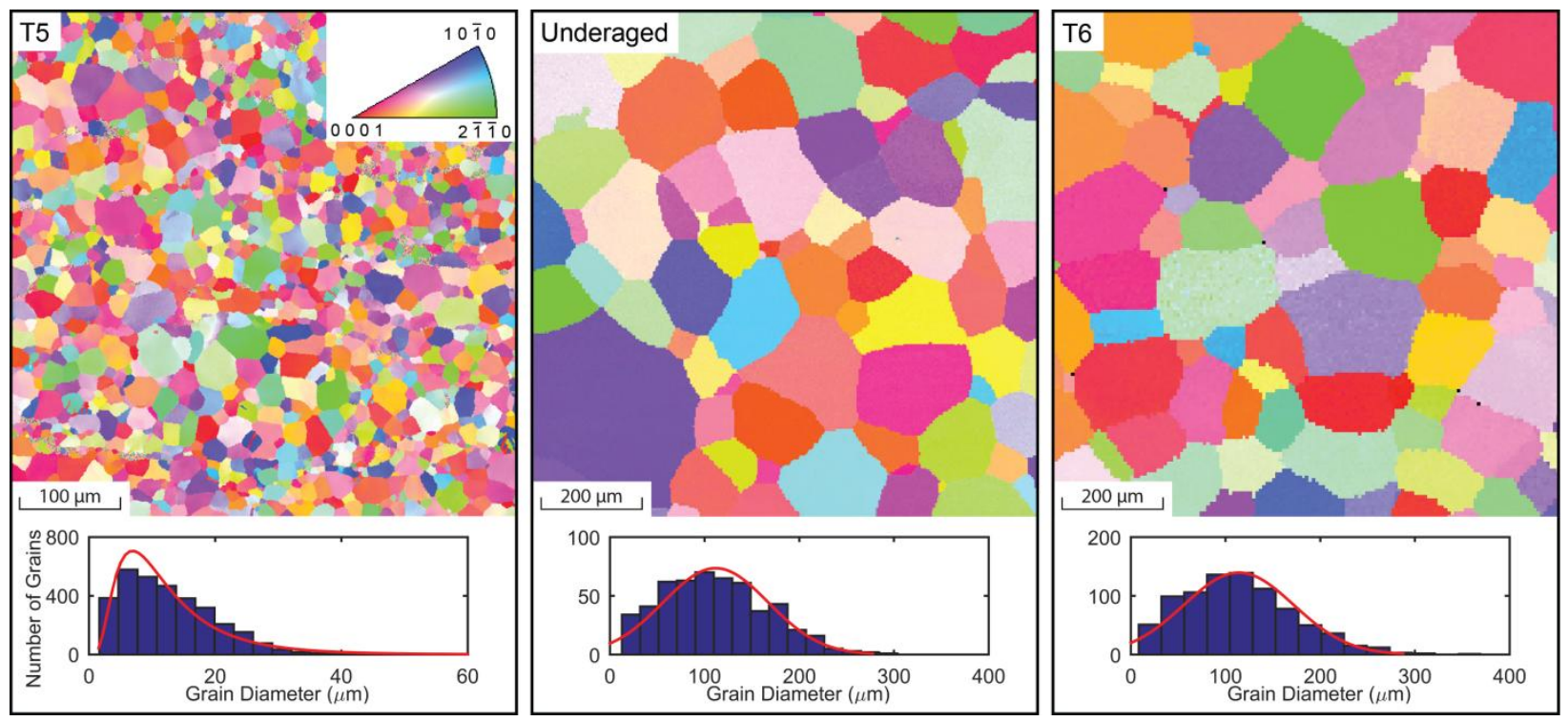

Figure 1: Representative microstructures and grain size distributions of T5, underaged, and T6 conditions of WE43.

Table 1 - Mechanical and Microstructural Properties of WE43 (Tensile properties are from Githens 2015)

\begin{tabular}{llllll}
\hline $\begin{array}{l}\text { Microstructural } \\
\text { Condition }\end{array}$ & $\begin{array}{l}\text { Elastic } \\
\text { Modulus (GPa) }\end{array}$ & $\begin{array}{l}\text { Tensile Yield } \\
\text { Strength (MPa) }\end{array}$ & UTS (MPa) & $\begin{array}{l}\text { Percent } \\
\text { Elongation }\end{array}$ & $\begin{array}{l}\text { Grain Size } \\
(\boldsymbol{\mu m})\end{array}$ \\
T5 & 43.5 & 265 & 335 & 19 & $13 \pm 7$ \\
Underaged & 43.5 & 139 & 235 & 15 & $112 \pm 55$ \\
T6 & 43.5 & 159 & 243 & 15 & $114 \pm 58$ \\
\hline
\end{tabular}

The crystallographic texture produced by each treatment was investigated using EBSD (Figure 2). Each of the three conditions featured a medium strength basal texture, with 2.90, 4.10, and 3.35 multiples of random distribution (m.r.d.) observed in the T5, underaged, and T6 conditions respectively, as expected in hot-rolled magnesium [36]. Basal poles were aligned perpendicular to the rolling plane, i.e. parallel to the normal direction (ND) of the plate.
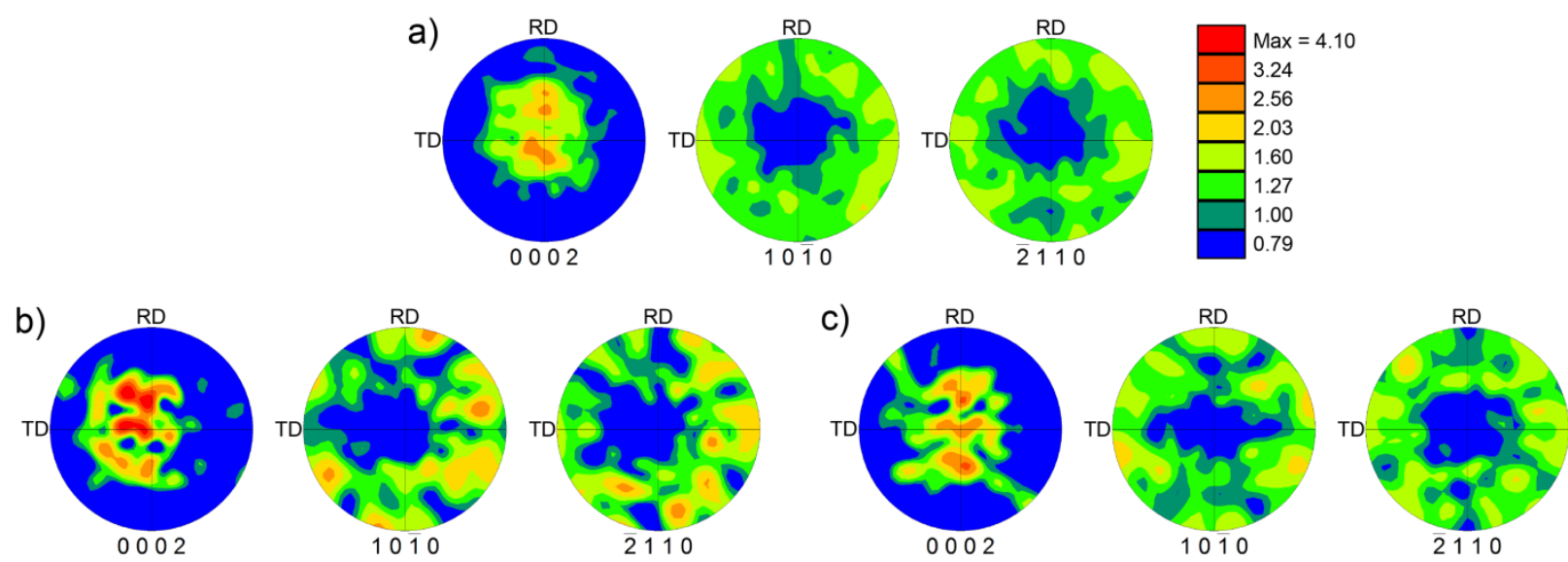

Figure 2: Texture maps from the a) T5, b) underaged, and c) T6 conditions of WE43 showing a clustering of basal poles around the normal direction of the rolled plate. 
In order to investigate the matrix strength of the heat treatments of WE43 without the effect of grain boundaries, hardness testing was conducted using a Hysitron Triboindenter. Nanohardness indents of approximately $1 \mu \mathrm{m}$ in width were produced using $2000 \mu \mathrm{N}$ of force in the center of grains, away from grain boundaries. Significant differences in hardness were observed for the three heat treatment conditions (Table 2), although not as significant as the observed differences in macroscopic tensile properties (Table 1).

Table 2 - Nanoindentation Hardness of WE43

\begin{tabular}{ll}
\hline $\begin{array}{l}\text { Microstructural } \\
\text { Condition }\end{array}$ & Hardness (GPa) \\
T5 & $1.58 \pm 0.10$ \\
Underaged & $1.35 \pm 0.22$ \\
T6 & $1.19 \pm 0.14$ \\
\hline
\end{tabular}

\subsection{Specimen Preparation}

Cylindrical fatigue specimens with a reduced gage section $4 \mathrm{~mm}$ in diameter and $7.5 \mathrm{~mm}$ in length were machined such that the longitudinal axis of the specimens aligned with the rolling direction (Figure 3), following standards in [37]. For short crack growth specimens, diametrically opposed surface flats were machined into the gage sections to facilitate tracking of fatigue crack growth and crystallographic analysis using EBSD. Short crack growth specimen surfaces were prepared by hand grinding with $\mathrm{SiC}$ paper and polishing with diamond solution, followed by electropolishing in a solution of three parts by volume $85 \%$ phosphoric acid $\left(\mathrm{H}_{3} \mathrm{PO}_{4}\right)$ and five parts by volume $95 \%$ ethanol for 30 minutes. Approximately $30 \mu \mathrm{m}$ was removed from the surface by electropolishing. The majority of the fatigue life specimens with no machined flats were prepared by a combination of low stress grinding and electropolishing, and some were prepared by low stress grinding only.

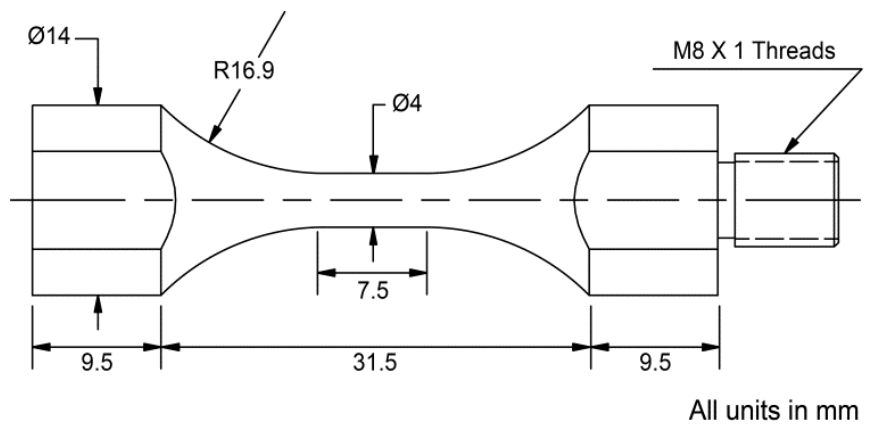

Figure 3: Ultrasonic fatigue specimen for WE43 magnesium. 
To investigate short crack growth behavior, micro-notches were machined in the gage flats to act as crack initiation sites, using an FEI Quanta 200 3D focused ion beam (FIB) equipped with a gallium ion source operating at 30kV and a probe current of 5.0 nA. Notches were machined perpendicular to the loading direction at the centerline of the specimen and each had a length of $100 \mu \mathrm{m}$, a width of $6 \mu \mathrm{m}$, and an approximate depth of $40 \mu \mathrm{m}$. In most cases, three notches, centered about the midsection of the gage length and separated by $2 \mathrm{~mm}$, were machined in each specimen.

\subsection{Experimental Procedures}

\subsubsection{Characterization of Fatigue Life}

To investigate the low stress, long life regimes where microstructure features dominate fatigue life, ultrasonic fatigue testing was used to perform both fatigue life studies and small crack growth measurements in a practical time frame. Fatigue life behavior was determined using ultrasonic fatigue instrumentation described in [38], operating at a testing frequency of approximately $20 \mathrm{kHz}$ and at a stress ratio of $\mathrm{R}=-1$ at room temperature in laboratory air (Figure 4). The mechanics of ultrasonic fatigue and recent developments are reviewed in [4,37]. For each test, constant displacement amplitudes were maintained to produce constant stress amplitudes. Intermittent cycling (200 ms ultrasonic pulse and $5 \mathrm{~s}$ pause) was used to minimize the heat generation associated with high frequency loading. Contact thermocouples were used to periodically measure the temperature of the specimen, and forced-air cooling was used to maintain the temperature below $35^{\circ} \mathrm{C}$. Fatigue life specimens were cycled until failure or to $10^{9}$ cycles, which was considered a runout. In a number of cases, underaged and T6 specimen runouts were stepped in increments of $10 \mathrm{MPa}$ to make efficient use of specimens. Failures resulting from step tests were tracked separately and fatigue results both with and without step tests were analyzed, as detailed in the results section. 


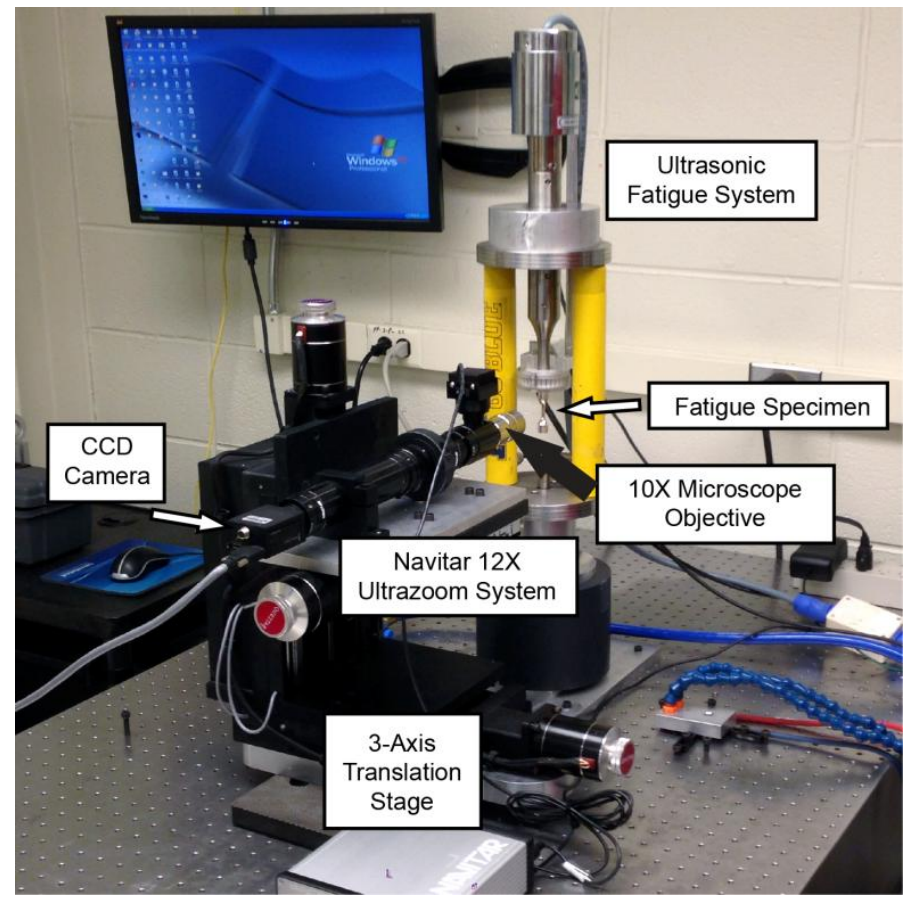

Figure 4: Ultrasonic fatigue instrumentation configured for fatigue life and short crack growth tests in laboratory air.

While most of the fatigue life and short crack growth studies were conducted in laboratory air, as described in the next section, selected high resolution crack initiation and short crack growth studies were conducted using recently developed ultrasonic instrumentation operating in a scanning electron microscope (UFSEM). This allowed in situ observation of damage accumulation and fatigue crack growth on the scale of microstructural features. Details of the instrumentation and its operation for in situ testing in a Philips XL30 ESEM can be found in [39]. In the present study, the UFSEM system was used with a Tescan Mira3 SEM for micro-scale characterization of cyclic damage and crack propagation at high spatial resolution, as shown in Figure 5. 


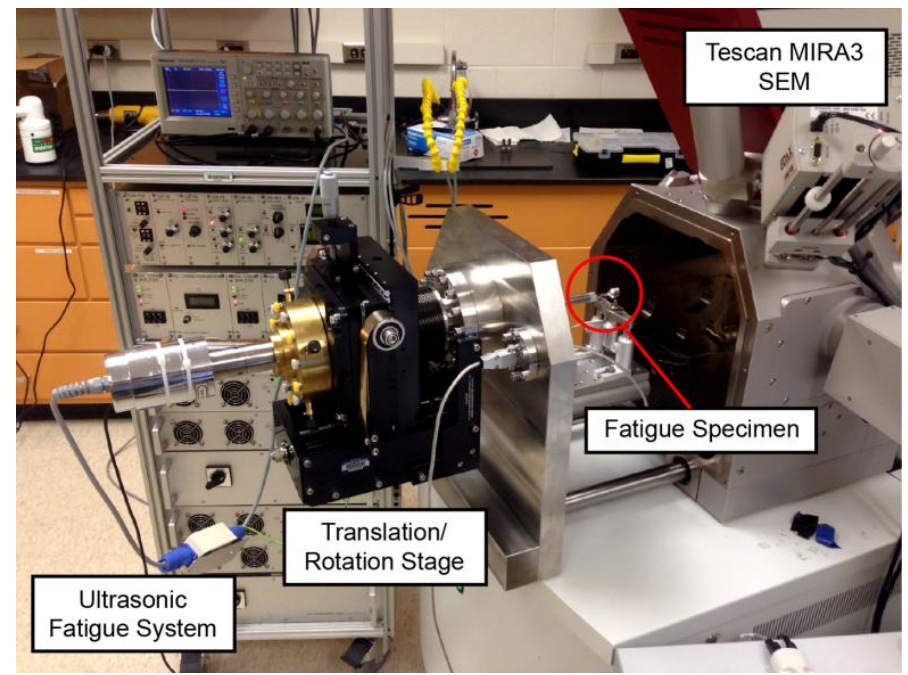

Figure 5: Integrated ultrasonic fatigue and scanning electron microscopy system (UFSEM) for in situ fatigue investigations and fatigue in vacuum.

\subsubsection{Characterization of Fatigue Crack Growth Behavior}

For short crack growth tests, FIB machined micronotches were centered about the gage midsection. No attempt was made in the present study to locate the notch tips in specific microstructures, and therefore, potential notch tip initiation sites sampled a variety of microstructural neighborhoods (Figure 6). Notch tip microstructural neighborhoods were characterized prior to fatigue using EBSD. Short crack growth tests were conducted at a frequency of approximately 20 $\mathrm{kHz}$ and at a stress ratio of $\mathrm{R}=-1$ at room temperature in laboratory air, with a constant maximum stress of $85 \mathrm{MPa}$, which assuming the notch to be a sharp crack gave a $\Delta \mathrm{K}$ of 0.75 . Observations of fatigue crack growth were made using a Navitar 12x Ultrazoom lens system equipped with a 10x Mitutoyo infinity corrected objective and a 5-megapixel CCD (Point Grey GRAS-50S5C). Cycling was paused every 25,000 to 30,000 cycles to observe fatigue damage and crack progression, and to capture micrographs for calculation of crack growth rates. Stress intensity factors were calculated using the equations of Newman and Raju [40] for a surface crack in a finite elastic plate, where c/a was assumed to be unity. Fatigue crack growth rates were calculated using a seven-point sliding polynomial method [41]. 


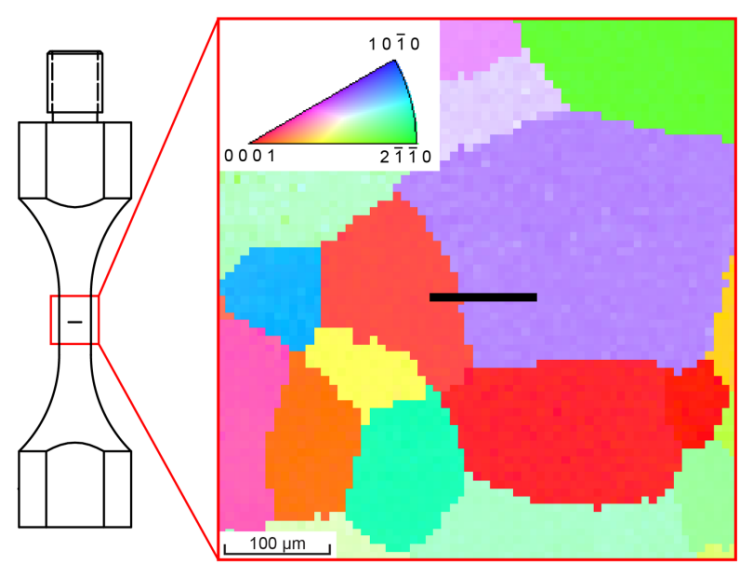

Figure 6: Diagram of FIB micro-notch placement in a WE43 ultrasonic fatigue specimen, and EBSD characterization of surrounding microstructure.

Selected short crack growth tests were performed using the UFSEM system in both laboratory air and in vacuum at pressures at or below $2.8 \times 10^{-3} \mathrm{~Pa}$. The air tests were conducted using the UFSEM load frame external to the SEM to allow rapid insertion of the entire system in the SEM without the need to remove the specimen from the ultrasonic fatigue instrument. This greatly facilitated examination of the crack progression through the microstructure. In situ crack growth tests (SEM vacuum of $2.8 \times 10^{-3} \mathrm{~Pa}$ ) were run at a constant maximum stress of $85 \mathrm{MPa}$ in most cases. Intermittent cycling (200 ms pulse and 9s pause) was used to minimize the heat generation associated with high frequency loading. Each pulse resulted in approximately 4000 fatigue cycles. Cycling was paused every 4,000 (1 pulse) to 400,000 (approximately 100 pulses) cycles, depending on fatigue crack growth rate, to observe fatigue damage and crack progression, and to capture micrographs for subsequent determination of crack growth rates.

\subsubsection{Characterization of Fatigue Fracture Surfaces}

Fatigue crack initiation sites produced in the un-notched fatigue life specimens were examined by fractography using the Tescan Mira3 SEM to better understand the role of microstructure in crack initiation. Specifically, the spatial orientation of fracture facets present at or near crack initiation sites was characterized using a quantitative tilt fractography technique described in detail in [42], which is based on the photogrammetric analysis of two fractographs of a facet taken at two different tilt angles.

The microstructural dependence of fatigue crack paths was studied using two approaches. The fatigue crack paths on the electropolished surface flats of the micronotched specimens were characterized from their initiation at the crack tip through their growth to final failure. EBSD was used to determine if crack paths favored specific crystallographic paths in 
individual grains. This was done by comparing the surface crack path with slip traces for particular slip systems. Finally, fractography was used to characterize the fatigue fracture surface morphology as the crack propagated from the micronotches or the natural initiation sites to final failure.

\section{Results}

\subsection{Effect of Heat Treatment on Fatigue Life Behavior}

The S-N data for the three heat treatments of WE43 examined in this study are shown in Figure 7. For the underaged and T6 conditions, step tests were performed in an attempt to characterize the high-scatter, long-life portions of the S-N curve characteristic of the VHCF fatigue regime, and these data are marked in Figure 7. The T5 curve includes specimens with either low-stress ground only or low-stress ground plus electropolished surfaces, while all underaged and T6 fatigue specimens received a final electropolish. Surface preparation appeared to play no role in fatigue life. In the T5 condition, all failures initiated at surface sites, while in the underaged and T6 conditions, 4 of 16 fatal cracks initiated at subsurface

sites. Subsurface initiation occurred in the lower stress, longer life regime (Table 3). The fatigue strengths at $\mathrm{N}=10^{9}$ cycles are $110 \mathrm{MPa}$ for the $\mathrm{T} 5$ condition and $65 \mathrm{MPa}$ for both the underaged and T6 conditions. In each condition, the S-N curve appears to have a generally continuous decreasing trend without a horizontal asymptote. The fatigue ratios $\left(\sigma / \sigma_{\text {UTS }}\right)$ for the T5, underaged, and T6 conditions at $10^{9}$ cycles are $0.33,0.28$, and 0.27 , respectively. Ogarevic and Stephens have reported that the fatigue ratio at $\mathrm{N}=10^{8}$ cycles for wrought magnesium alloys in fully reversed loading at conventional frequencies was between 0.25 and 0.5 , with higher ratios for higher strength alloys [43]. These results indicate that each of the three conditions of this alloy feature fatigue strength ratios at the lower end of the previously reported range. 


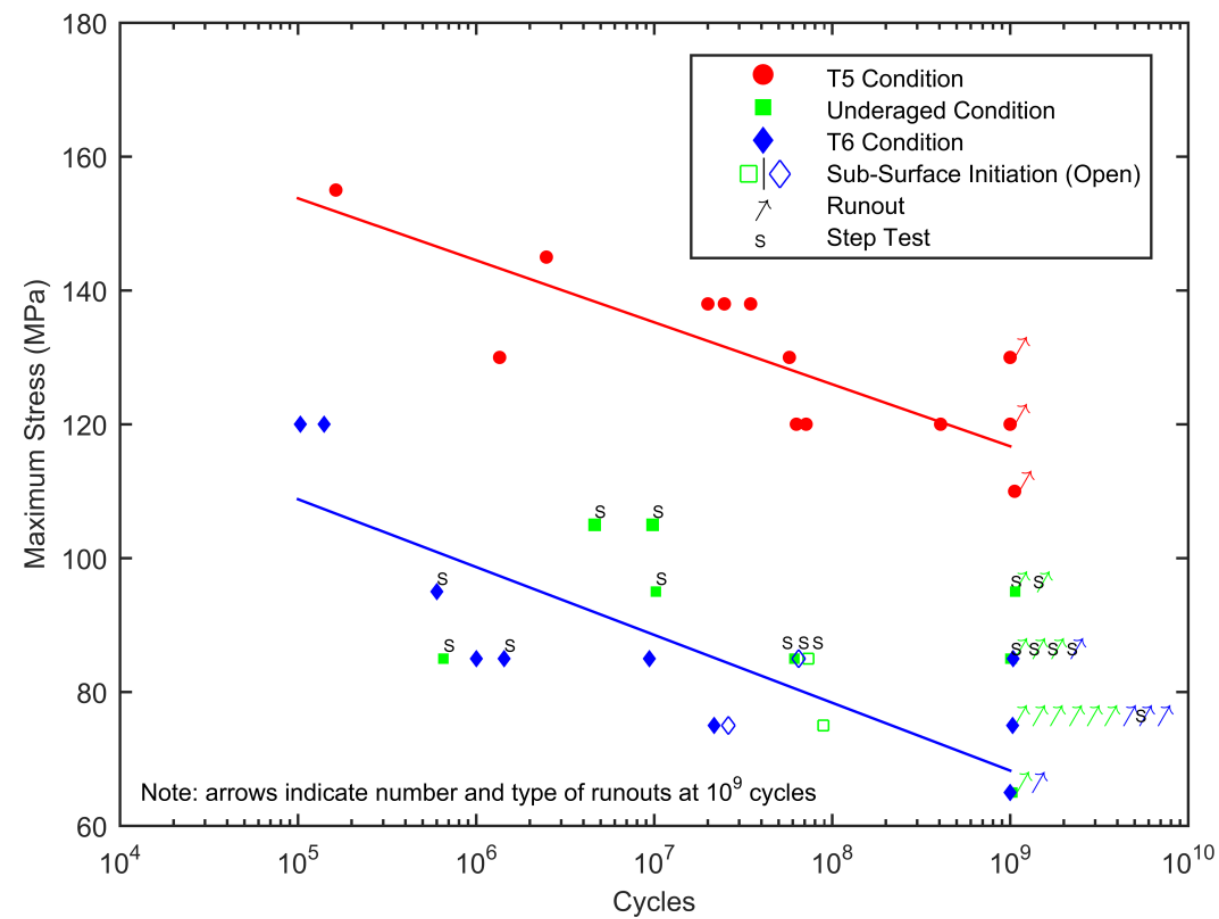

Figure 7: Fatigue lifetime behavior of the three conditions of WE43, with data points from step tests indicated. The similarities between the microstructures of the underaged and T6 conditions result in little difference in fatigue lifetime behavior, which becomes more evident with the inclusion of step tests. Subsurface initiation was observed in the coarsegrained conditions at high lifetimes, and is detailed in Table 3.

Table 3 - Subsurface Fatigue Life Failures

\begin{tabular}{lll}
\hline $\begin{array}{l}\text { Microstructural } \\
\text { Condition }\end{array}$ & $\begin{array}{l}\text { Maximum Stress } \\
\text { (MPa) }\end{array}$ & Lifetime \\
\hline Underaged & 75 & $8.91 \times 10^{7}$ \\
Underaged & 85 & $7.34 \times 10^{7}$ \\
T6 & 75 & $2.61 \times 10^{7}$ \\
T6 & 85 & $6.47 \times 10^{7}$ \\
\hline
\end{tabular}

The underaged and T6 conditions exhibited similar microstructures (grain size and precipitate structure) and nearly identical fatigue behavior, indicating that differences in aging times employed here had little influence on fatigue life. Fatigue strength in the stronger T5 condition is approximately $40 \mathrm{MPa}$ higher than that observed for the coarse-grained underaged and T6 conditions. In the present study, a key question arises as to whether this notable difference in fatigue strength can be attributed to differences in short crack growth rates or crack initiation lifetime or perhaps both. In sections 4.2 and 4.3 we address these possibilities. 


\subsection{Crack Initiation Behavior}

\subsubsection{Surface Crack Initiation}

For fatigue failures in the T5 material, shown in Figure 7, all specimens failed from surface initiated cracks and in almost all cases, facets were found at or near the initiation site (Figure 8a,b). These facets were occasionally characterized by roughness on the fatigue facet surface (Figure 8a), however many smooth, featureless facets were also observed (Figure 8b). Chemical analysis (energy-dispersive spectrometry, or EDS) showed no presence of oxide films or other inclusions at these sites, indicating that the surface roughness may be the result of crack face contact during fully reversed loading. In addition to large single facets, groupings of multiple favorably oriented facets were also observed at initiation sites in samples from the T5 condition. Two of ten initiation sites had no facets associated with them. Again, chemical analysis of these sites showed no presence of oxides or inclusions. Rough surfaces were observed on both faceted features and nonfaceted features.
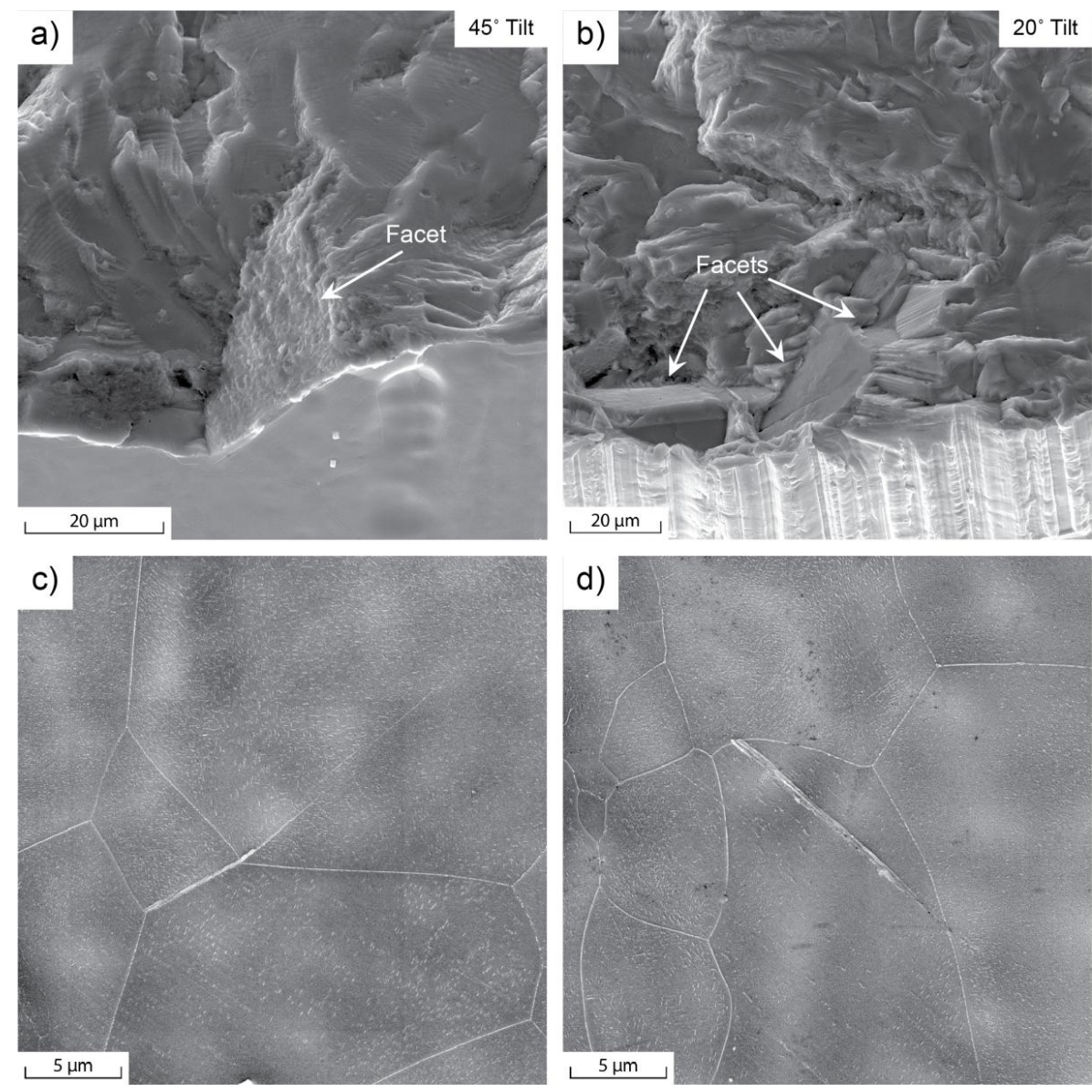

Figure 8: Crack initiation sites in T5 WE43 showing a) single facets, b) groupings of multiple facets, and fatigue damage sites at c) intergranular and d) transgranular locations. 
Evidence of other non-fatal crack initiation sites were observed on the surfaces of failed T5 fatigue specimens, but the cyclic damage and fatigue crack propagation had not progressed beyond one or two grain diameters. These very short nonfatal cracks occurred both away from grain boundaries (Figure 8d), and at or very near grain boundaries (Figure 8c), with the latter locations dominating. Non-fatal cracks initiated at or near grain boundaries either arrested at triple points or propagated through triple points into neighboring grains along predominantly basal crystallographic slip planes. Cracks that initiated in grain interiors formed through slip accumulation along predominantly basal crystallographic planes, and often arrested at grain boundaries.

Crack initiation behavior in unnotched fatigue specimens in the underaged and T6 conditions was essentially identical, with both surface and sub-surface initiation observed for the fatal cracks for both heat treatments. Large facets were present at most surface crack initiation sites (Figure 9). In contrast with the T5 condition, faceted surface initiation sites in the coarsegrained conditions were always limited to a single initiating feature, and in some cases, the initiation site could be narrowed to only a portion of a single facet (Figure 9a,b). In these cases, micro-beach marks, discussed in Section 4.3.3, and other indicators of crack propagation were used to identify the region of initiation. Very short non-fatal cracks along grain boundaries were generally observed to lie along curved boundaries, and to only propagate along a portion of that boundary before growing tangentially into the grain interior along a crystallographic slip plane (Figure 9c). Although transgranular slip was occasionally observed, no non-fatal cracks were observed that initiated along those slip planes away from grain boundaries.
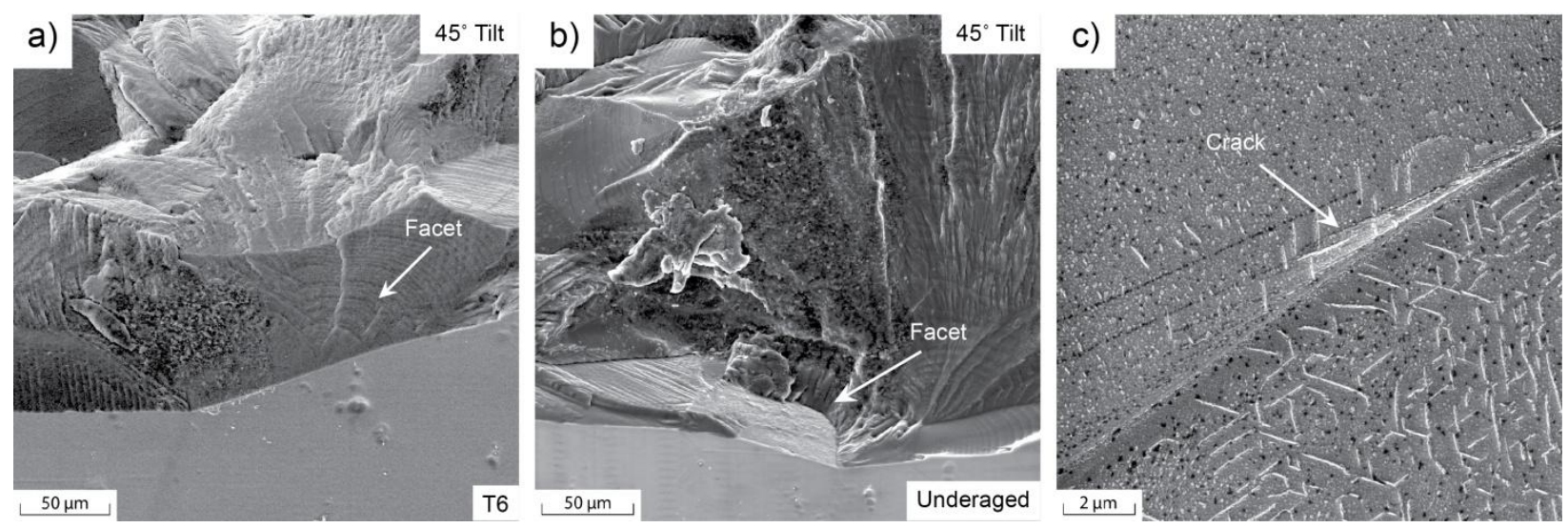

Figure 9: Crack initiation sites in coarse-grained WE43 showing a), b) large single facets, and c) non-fatal crack initiation site at a grain boundary.

The projected diameters and orientations (angle of the plane normal relative to the loading direction) of facets found at or near the initiation sites for the T5, underaged, and T6 condition (coarse grain) fatigue life specimens were analyzed and the 
results are shown in Figure 10. The largest facet dimension was larger than the average grain diameter for essentially all of the facets that were measured. For the T5 condition, these facets were generally oriented for high resolved shear stress, with plane normals forming an average angle of $48^{\circ} \pm 10^{\circ}$ with the loading direction (Figure 10a). Figure 10b shows projected diameters and orientations for initiating facets in the coarse-grained heat treatment conditions. In these conditions, approximately sixty percent of the facets were larger than the average grain size at their largest dimension, and exhibited an average size of $155 \pm 84 \mu \mathrm{m}$. Their orientations, while still favorable for slip, tended to lie closer to the generalized fracture plane with an average angle of $34^{\circ} \pm 9^{\circ}$ formed between facet normals and the load direction.
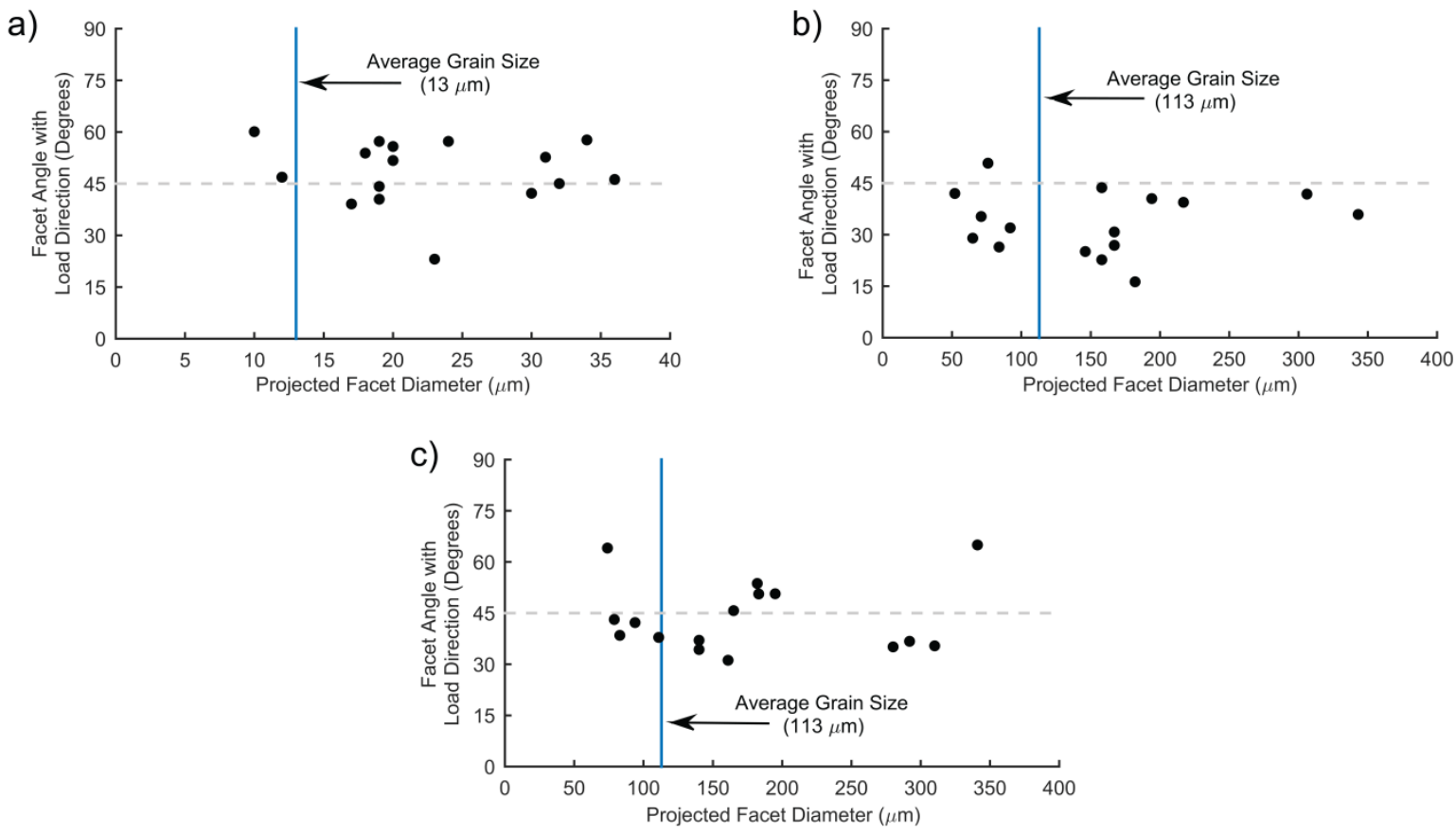

Figure 10: Diameters and orientations (angle of plane normal with respect to load) of facets present at a) T5 surface initiation sites, b) underaged and T6 surface initiation sites, and c) underaged and T6 subsurface initiation sites.

\subsubsection{Subsurface Crack Initiation}

In the coarse-grained underaged and T6 conditions, four of sixteen fatigue samples failed by subsurface crack initiation and subsequent fatigue crack growth (Figure 7). Subsurface initiation occurred only at the lowest stresses (75 and $85 \mathrm{MPa}$ ) at relatively long fatigue lifetimes $\left(>10^{7}\right)$ and even at these low stresses some specimens failed from surface initiated fatigue cracks. The measured fatigue lives from specimens with subsurface initiation sites did not appear to be significantly different from specimens in which the fatal crack initiated on the surface. As noted previously, subsurface initiation is absent in the T5 condition, at all stress levels and lifetimes. Interestingly, the features associated with subsurface initiation 15 
and early fatigue crack growth are quite similar to the fracture surface morphology observed in crack propagation tests in vacuum (Figure 16), as presented in Sections 4.3.2 and 4.3.3.

Typical examples of subsurface crack initiation sites are shown in Figure 11. The region of initiation and very early crack growth was characterized by a relatively planar fracture surface, with surface roughness on facets (Figure 11a). At each initiation site, a single initiating feature could not be identified, although large facets were found at each initiation zone. Occasionally, multiple large facets were found grouped in V-shaped (chevron) formations (Figure 11b) or with very similar orientations, forming a "superfacet" (Figure 11a). These facets exhibited both smooth, relatively featureless surfaces and surface roughness characteristic of fatigue crack growth in vacuum. Facets measured at subsurface initiation sites exhibited an average projected diameter of $177 \pm 87 \mu \mathrm{m}$, well above the average grain size of $114 \mu \mathrm{m}$ in the underaged and $\mathrm{T} 6$ conditions. Subsurface facets are oriented for high resolved shear stress, with plane normals forming an average angle of $44^{\circ} \pm 10^{\circ}$ with the loading direction (Figure 10c). On average, subsurface facets were slightly larger than those present at surface initiation sites, and were oriented slightly more favorably for high resolved shear (e.g., $44^{\circ}$ versus $34^{\circ}$ ).
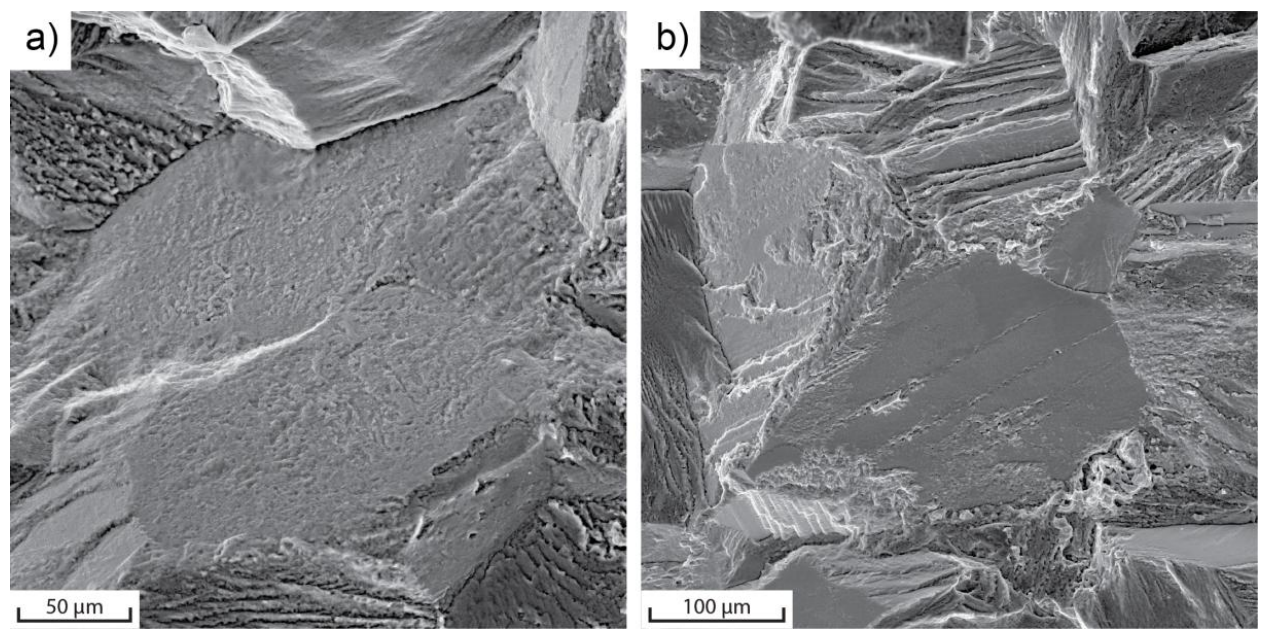

Figure 11: Subsurface crack initiation sites in large-grained WE43 showing a) "supergrain" groupings of facets and b) chevron groupings of facets.

\subsection{Fatigue Crack Growth Behavior}

\subsubsection{Fatigue Crack Growth in Laboratory Air}

The crack growth behavior of the three microstructural conditions of WE43 is shown in Figure 12 for tests conducted in laboratory air using FIB micronotched specimens. In the two coarse-grained microstructures there were significant fluctuations in crack growth rates, especially at $\Delta \mathrm{K}$ less than approximately $1.5 \mathrm{MPa} \cdot \mathrm{m}^{1 / 2}$, and characterized mainly by 
significant dips in crack growth rate and occasional crack arrests that are likely associated with microstructure. In the T5 condition, crack growth rates were relatively unaffected by local microstructure, exhibiting few resolvable crack arrests or fluctuations in crack growth rate. It should be noted that such fluctuations are much more difficult to detect in fine grain materials, as significantly more crack length measurements must be made to resolve changes in crack growth rate over such small distances, and the limit of resolvability in cycle count between measurements is controlled by the ultrasonic pulse length, with a lower bound of approximately 4000 cycles. Above $1.5 \mathrm{MPa} \cdot \mathrm{m}^{1 / 2}$ average crack growth rates for the three conditions converge to between approximately $1 \cdot 10^{-9}$ and $6 \cdot 10^{-9} \mathrm{~m} /$ cycle.
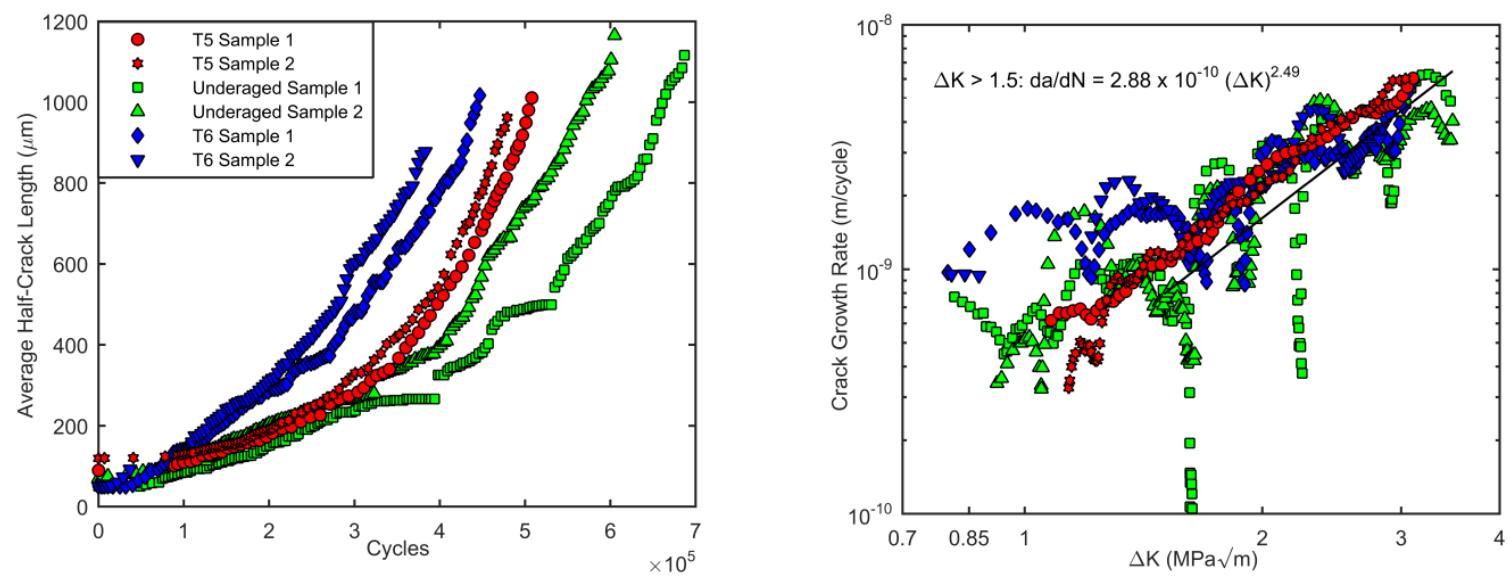

Figure 12: Crack growth behavior in the three conditions of WE43 including a vs. $\mathrm{N}$ and da/dN vs. $\Delta \mathrm{K}$ showing microstructural effects in the underaged and $\mathrm{T} 6$ conditions.

Crack paths were investigated on specimen surfaces by correlating SEM images of the crack with EBSD scans of the local microstructure collected before fatigue testing. In each condition, surface crack propagation was found to be a mix of crystallographic transgranular growth predominantly along basal planes and non-crystallographic transgranular growth. Intergranular growth was only observed occasionally. Examples of crack path profiles for the three conditions are shown in Figure 13. In each condition, cracks tended to reorient at grain boundaries to follow favorable crystallographic planes, often resulting in deflection of the crack path away from the macroscopic crack plane. In the T5 condition, as a result of the fine grain size, these deflections at grain boundaries resulted in only short departures of the crack from the generalized crack plane. In the underaged and T6 conditions, the larger average grain size resulted in more significant departures from the macroscopic crack plane. 

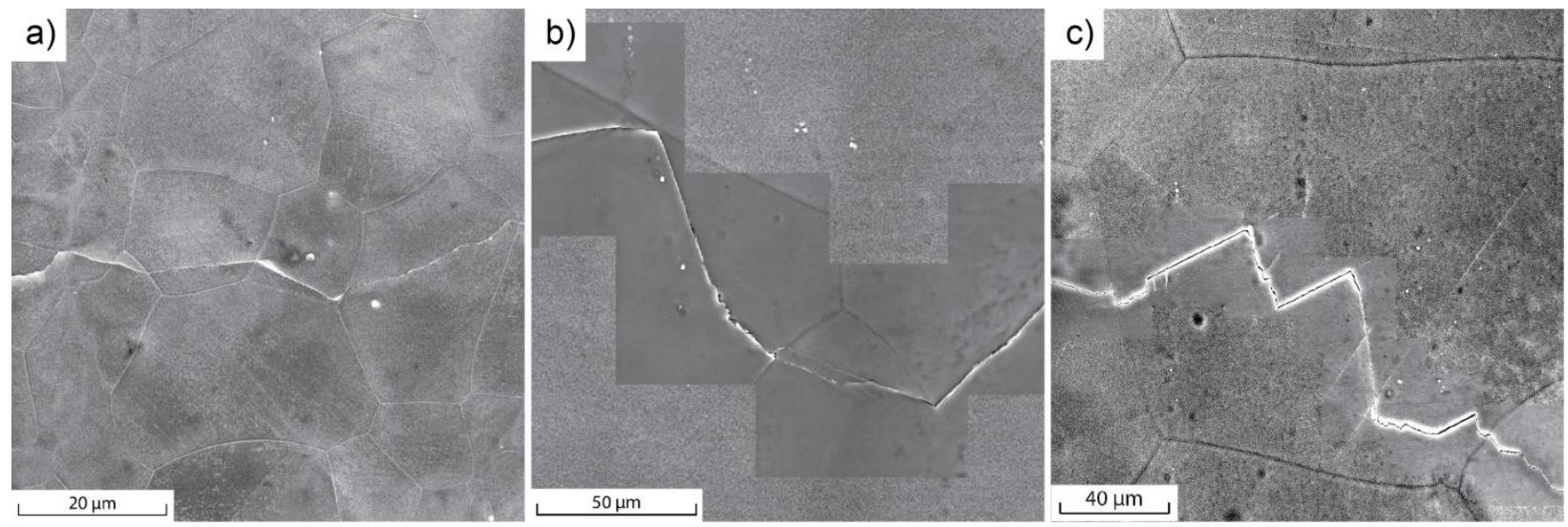

Figure 13: Surface crack profiles showing apparent crystallographic propagation and deflection of short cracks at grain boundaries in the a) T5, b) underaged, and c) T6 conditions of WE43.

\subsubsection{Fatigue Crack Growth in Vacuum}

As subsurface crack initiation and growth essentially occur in vacuum, crack growth tests were conducted in a vacuum environment to explore potential differences in subsequent short crack propagation rates between internal initiation (vacuum) and surface initiation (air) and to investigate possible differences in fatigue behavior. The UFSEM system was used to provide the vacuum environment for a fatigue crack propagation study where periods of growth were alternately in vacuum or in air. In vacuum, stress amplitudes matching those used in laboratory air experiments (85 MPa) resulted in either crack arrest, significantly lower crack propagation rates, or minimal crack propagation leading to crack arrest (Figure 14). In general, crack growth rates in vacuum were nearly two orders of magnitude lower than in laboratory air. When periods of crack growth in air were followed by testing in vacuum, an immediate and significant decrease in crack propagation rate occurred. Following a return to laboratory air, crack growth resumed as if uninterrupted. Increased stress amplitudes (100 MPa) in vacuum testing were used to propagate cracks previously grown to multiple grain diameters in laboratory air at $85 \mathrm{MPa}$. Again crack propagation rates were significantly lower in vacuum than those observed in laboratory air, even for cracks propagated in air at lower stress amplitudes. 

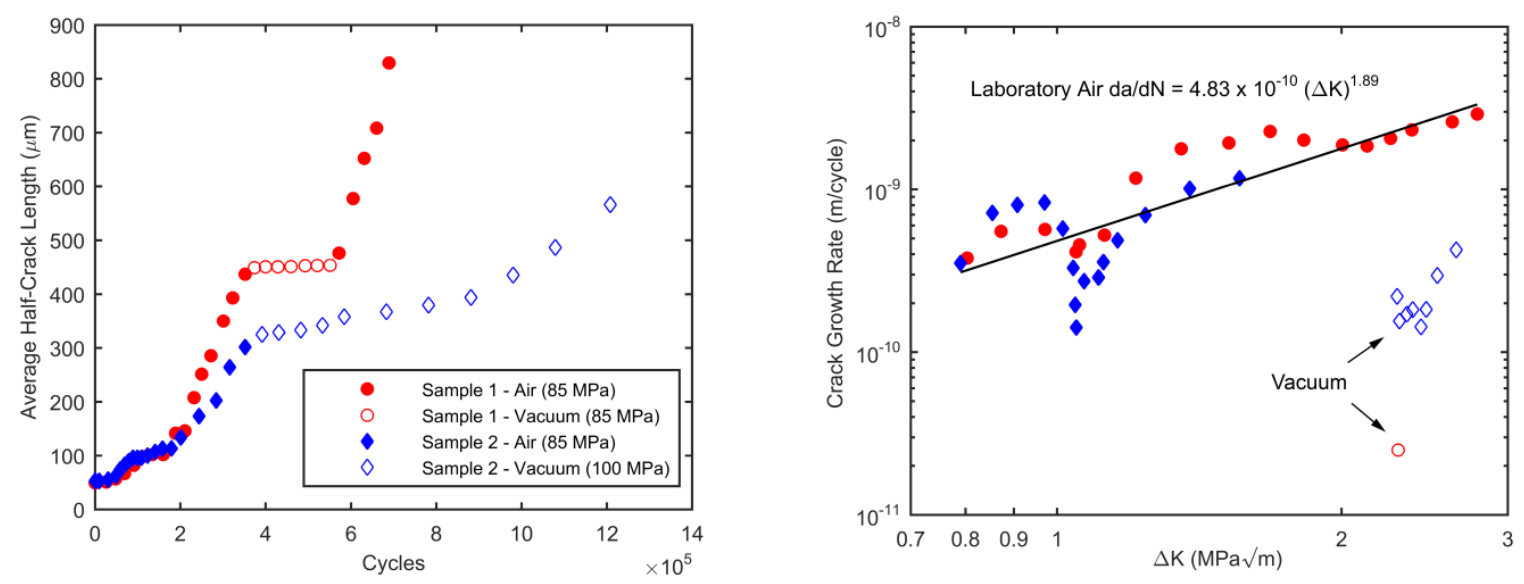

Figure 14: Crack growth of underaged WE43 in vacuum results in crack arrest or significantly reduced growth rates as compared to laboratory air. Environmental transitions show immediate effects on crack growth rate.

\subsubsection{Fracture Surface Morphology}

SEM fractographic examination was used to further investigate the effect of microstructure on crack growth behavior in both laboratory air and vacuum environments. An overview of a typical fracture appearance for a T5 failure that propagated from a micronotch in laboratory air is shown in Figure 15a, where the early, intermediate and later crack growth regions of interest are indicated. In the region nearest the FIB micro-notch, transgranular facets are in evidence, as illustrated in Figure 15b. At an intermediate crack length $\left(1.8 \mathrm{MPa} \cdot \mathrm{m}^{1 / 2}<\Delta \mathrm{K}<3.4 \mathrm{MPa} \cdot \mathrm{m}^{1 / 2}\right)$, the relatively featureless crack surfaces transitions to a rough region, characterized by transgranular propagation and the general absence of facets (Figure 1c). In this region, evidence of parallel features indicative of tearing and shear on the order of the grain size are present (Figure 15c). At $\Delta \mathrm{K}>3.4 \mathrm{MPa} \cdot \mathrm{m}^{1 / 2}$, this second region transitions to a flatter noncrystallographic transgranular morphology (Figure 15d). As expected, the early crack growth region (nearest the notch) exhibited the same features as those found near the natural initiation sites for surface initiated failures in laboratory air. A clear difference was observed between the morphology of fracture surfaces corresponding to fatigue in laboratory air and those corresponding to fatigue in vacuum, leading to the question of whether fatigue crack propagation from a micronotch in an in situ UFSEM test would yield fracture features similar to those observed from subsurface initiated fatigue cracks. To examine this further, a test was conducted where crack initiation and early propagation was conducted in laboratory air followed by further crack propagation in the SEM. 
a)
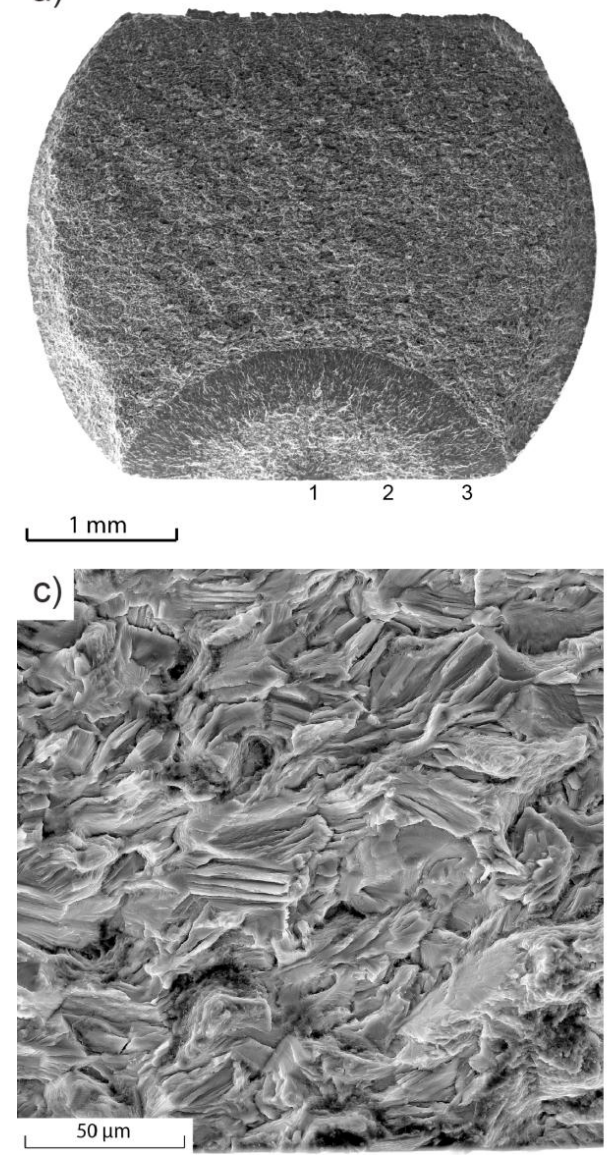
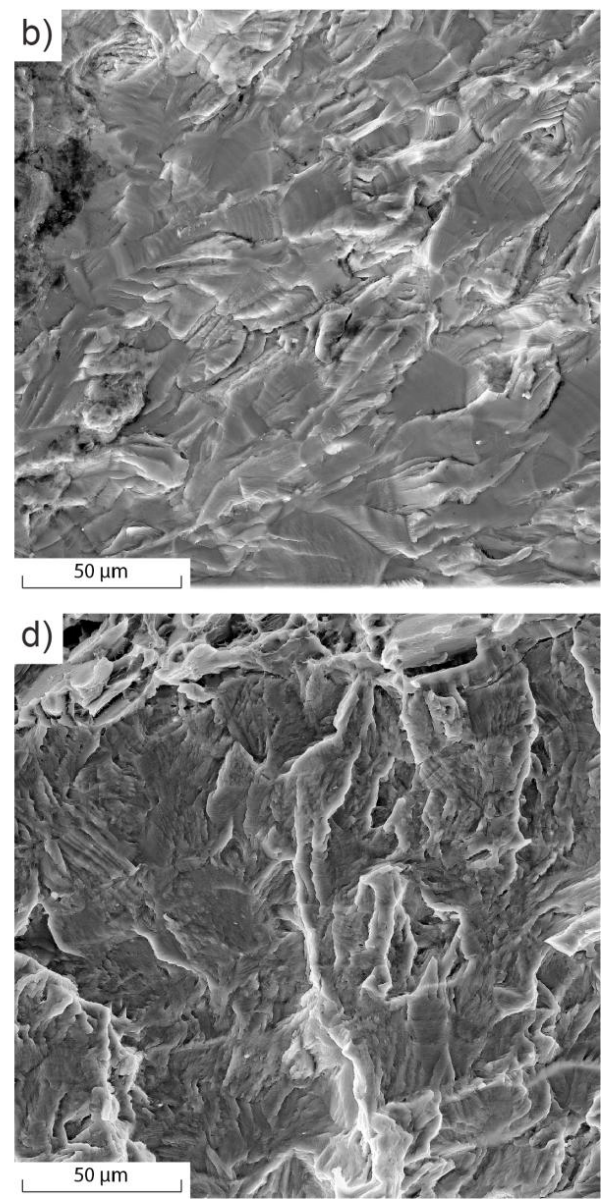

Figure 15: a) Macroscopic fracture surface of a T5 specimen showing 3 regions with distinct morphologies, b) first, corresponding to marker 1 . a heavily faceted region of crystallographic transgranular growth at low stress intensities, c) second, corresponding to marker 2, a rough transgranular region with lamellar structures at mid-range stress intensities, and lastly, d) smooth, non-crystallographic transgranular growth at higher stress intensities until sample failure corresponding to marker 3. 


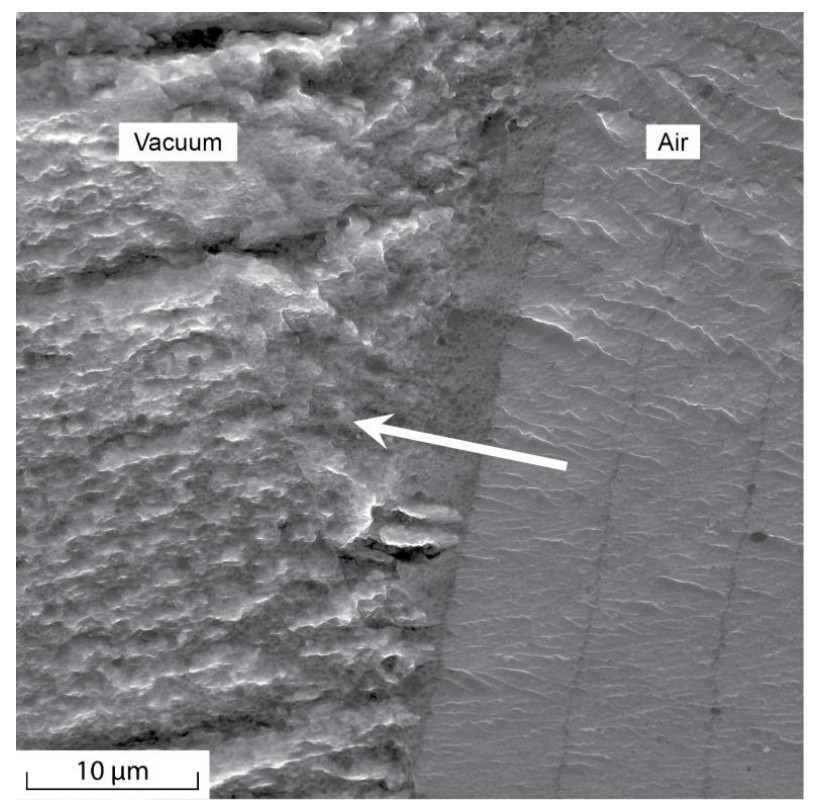

Figure 16: Fracture morphology in a WE43 sample fatigued in laboratory air and vacuum, showing a notable transition in fracture surface morphology as a result of the change in environment. Crack growth is from right to left in the direction of the arrow.

Figure 16 shows a scanning electron micrograph of a short fatigue crack growth specimen that was first fatigued in laboratory air with a maximum stress of $85 \mathrm{MPa}$. Crack growth was continued in vacuum with an increased maximum load of $100 \mathrm{MPa}$. A clear transition between two fracture surface morphologies is visible. While fracture surfaces from fatigue in laboratory air are generally featureless, regions from fatigue in vacuum exhibit more surface roughness. The effect of environment appears to be immediate, as the fracture surface abruptly changes at the air to vacuum transition and crack growth rates immediately responded to the change in gaseous environment as described in Figure 14. 
a)

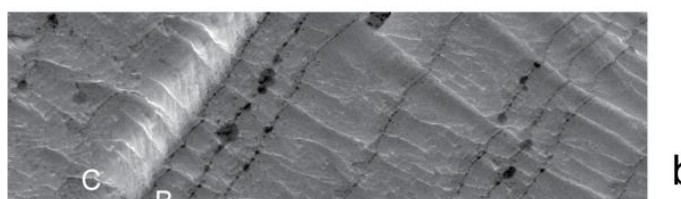

b)
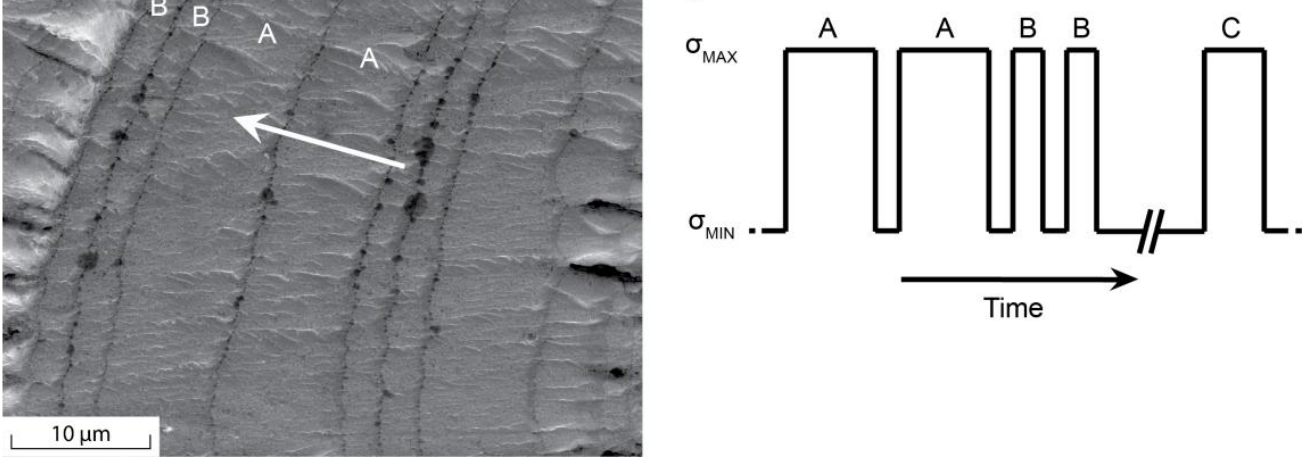

Figure 17: Fracture morphology in WE43 magnesium produced by crack propagation in laboratory air showing a) micro beach marks. Crack growth is from right to left, in the direction of the arrow. B) Differing pulse lengths (A, B, and C) produce micro-beach marks of different widths. Minor pauses ( $<1$ minute) produced the finer divisions visible between bands $\mathrm{A}$ and $\mathrm{B}$, while a longer pause (> 15 minutes) for characterization of the crack on the specimen surface in an SEM produced the more significant division between bands B and C.

Although fractographic investigation can provide some insight into crack propagation mechanisms, without a record of subsurface crack propagation, it cannot provide information on local crack growth rates. While it is possible in some cases to monitor crack propagation in three dimensions [31,44], it is interesting to note that in the present study regions of the fatigue fracture surfaces for tests conducted in air were often marked with microscopic indicators of crack advancement (Figure 17), which we term micro-beach marks. The micro-beach marks may aid in determining local crack growth rates. As shown in Figure 17b, these markings correlate directly with the cyclic loading history of the ultrasonic fatigue tests, where the distance between markings is proportional to the number of cycles in a given block of the load history. These periodic features are observed most easily in the large grained underaged and T6 conditions of WE43. In the finer grained T5 condition, the marks are present but more difficult to discern. In contrast to the fracture surfaces from fatigue in laboratory air, micro-beach marks are rarely observed on fracture surfaces corresponding to fatigue in vacuum, and when present tended to be irregular and very faint. Micro-beach marks are similar in appearance to the well studied fatigue phenomena of macroscopic beach marks or marker bands [44-47]. A calculation of crack growth rate based on the assumption that each micro-beach mark corresponded to crack growth during a single ultrasonic pulse (approximately 4000 cycles), yielded growth rates on the same order of magnitude as surface-measured crack growth rates for similar stress intensities. Thus, these micro-beach marks record both the location of the crack front on interior grains and allow the determination of short crack growth behavior relative to local microstructural features, including the calculation of local, 
subsurface crack growth rates in a manner similar to [48]. Figure 17 shows a region of markings of varying widths that correspond to sets of alternating long and short pulses used to locate successive crack fronts on SEM micrographs. Further studies are underway to use such markings to determine crack growth rates at various positions along the 3D crack front, as well as to understand the origins of the markings and the role of environment in their creation.

\section{Discussion}

Fatigue strength of three heat treatments (T5, underaged, and T6) of WE43 Mg alloy in the VHCF regime scaled with yield and tensile strength in a manner similar to the behavior observed by others in the LCF and HCF regimes for similar Mg alloys. In general, fatigue lifetimes in the VHCF regime are controlled by crack initiation and short crack growth. In the present study, since average short crack growth rates $(\mathrm{da} / \mathrm{dN})$ did not differ significantly for any of the three heat treatment conditions, we conclude that the overall VHCF S-N response is primarily a result of differences in fatigue crack initiation lifetimes. For the sake of analysis here, the primary microstructure variation among the three heat treatments is identified as grain size and matrix precipitate structure. The solution treatment applied to the as-received T5 alloy to produce the underaged and T6 microstructures increased the grain size by an order of magnitude (nominally from $13 \mu \mathrm{m}$ to $113 \mu \mathrm{m}$ ), as well as affecting matrix precipitate structure. A detailed analysis of precipitate structure, size, and volume fraction in the three conditions is beyond the scope of the present work, however, the role of microstructure variation on fatigue life can be inferred from the fractographic observations and related analyses. Thus in the succeeding discussion we examine the nature of fatigue crack propagation and initiation and the likely influences of grain size and matrix precipitate structure on fatigue lives of the three heat treatments of WE43 examined in this study.

\subsection{Crack Growth Behavior}

Although local variability in short fatigue crack growth rate was more evident in the coarse grained microstructures, especially for $\Delta \mathrm{K}$ less than $1.5 \mathrm{MPa} \cdot \mathrm{m}^{1 / 2}$, the average crack growth rates for the three heat treatments are similar and cannot explain the significant differences in S-N fatigue life behavior between the T5 condition and the two solution treated and aged microstructures. This is best shown by using the fatigue crack growth data to estimate fatigue lives when crack initiation lifetime is assumed to be zero. If fatigue crack behavior is assumed to follow a power law equation of the form shown in Equation 4.1, the constants $C$ and $m$ can be determined from a least squares fit of crack growth data (Figure 12). Integration of Equation 4.1 then provides an estimate of the number of cycles to propagate a crack (propagation life) as a function of crack length (Equation 4.2), with $a_{i}$ and $a_{f}$ representing initial and final crack lengths respectively. 
$N_{\text {Prop }}=\int_{a_{i}}^{a_{f}} \frac{\Delta K^{-m}}{C} d a$

(Equation 4.2 - Fatigue Life)

A representative power law equation was found by fitting the average short crack growth data for all three conditions at $\Delta \mathrm{K}$ higher than $1.5 \mathrm{MPa} \cdot \mathrm{m}^{1 / 2}$, where crack growth rates for the three conditions converged, resulting in coefficients of $C=$ $2.88 \cdot 10^{-10} \mathrm{~m} /$ cycle and $m=2.49$. In using equation 4.2 to estimate the propagation lifetime, initial crack lengths were taken to be half the average grain size for each heat treatment condition which is $6 \mu \mathrm{m}$ for the fine-grained $\mathrm{T} 5$ and $56 \mu \mathrm{m}$ for the coarse-grained underaged and T6 conditions. A final crack length of $2 \mathrm{~mm}$ (half the diameter of the ultrasonic fatigue specimen) was used for all calculations. The resulting estimates in Figure 18 show that fatigue lives in the VHCF regime are much longer than those that would occur if crack propagation was the dominant factor. This leads us to conclude that the VHCF lives are primarily dependent on the number of cycles to initiate a crack on the scale of the grain size. It also suggests that the variability in VHCF lives is due to variability in crack initiation lifetime. The estimates also lead to the possibility that in the $10^{5}-10^{6}$ region, the propagation of short cracks play a significant role in determining the overall fatigue life. 


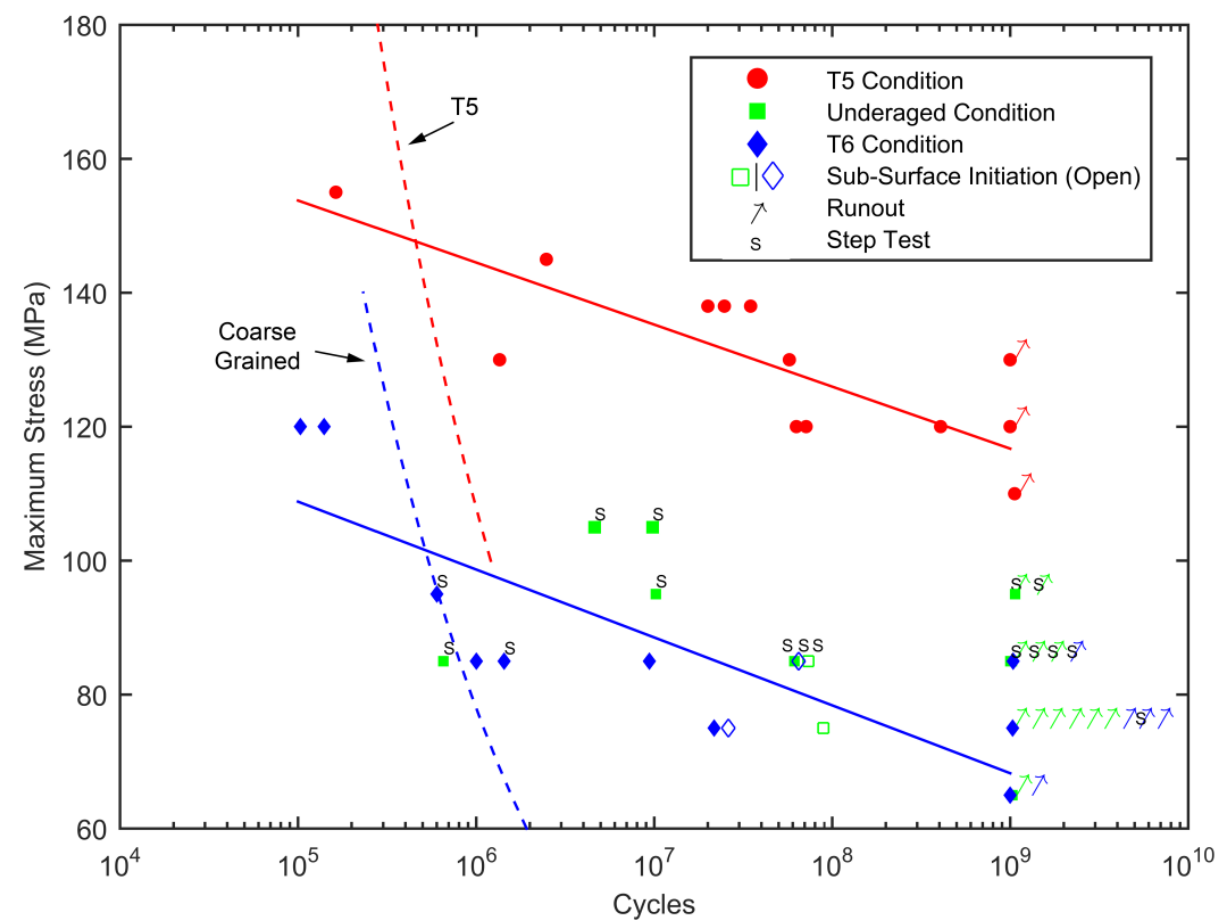

Figure 18: Estimates (dashed lines) of crack growth-controlled fatigue life based on integration of a power law crack growth behavior. The initial crack length for each condition was taken to be half the average grain sizes. The low lifetime estimates indicate that propagation life does not contribute significantly to total lifetime in the VHCF regime.

While grain boundaries are well known to often be significant barriers to slip transfer during deformation [49] and grain misorientation has been shown to significantly affect the resistance of boundaries to fatigue crack propagation [31,50], the influence of grain size on short fatigue crack propagation is not resolved. For example, in a short crack growth study of cast AM60B magnesium, Gall et al. noted that although small cracks interacted observably with microstructural features such as grain boundaries, the quantitative effect on overall crack growth rate was in some cases small [51]. Ravichandran has postulated that coarse-grained materials have a better resistance to fatigue crack propagation as a result of deflections at grain boundaries and the resulting reduction in the effective Mode I stress intensity factor at the crack tip [52]. Others, however, have postulated that the increased number of grain boundaries encountered in fine-grained materials slows crack advancement as compared to coarse-grained materials [24]. Although literature characterizing grain size effects on short crack growth behavior in magnesium are lacking, studies in aluminum are more extensive and corroborate the limited studies in magnesium. Investigations of the effect of grain size on fatigue crack growth rates by Turnbull and De Los Rios and Zurek et al. showed very similar crack growth rates in aluminum alloys with a wide range of grain sizes [53,54]. Despite this, Turnbull and De Los Rios demonstrated that a smaller grain size still resulted in increased fatigue strength. 
Similarly, Yue et al. showed that even when fatigue crack growth rates were slower for larger grain sizes in a $\mathrm{Mg}$ alloy, fatigue lives were still much greater in a microstructural condition with a finer grain size [55]. Horstemeyer et al. showed that a variation of up to two orders of magnitude in fatigue lives of an AZ91E magnesium alloy were the result of differences in the size of crack nucleation sites [56]. The relevant conclusion from Yue et al. is that the fracture energy and fatigue crack propagation results confirm well-established principles that coarse microstructures, by imposing tortuous crack paths, exhibit higher crack resistance than those microstructures where the crack path is more closely confined to the general crack plane. Horstemeyer et al. show, on the other hand, on the basis of S-N data, that fine-grained material has a higher fatigue strength than coarse-grained material due to the greater difficulty of fatigue crack initiation and early growth in small grains. Fatigue strength in WE43 followed the trend established by the works of Turnbull, De Los Rios, Horstemeyer et al. and Yue et al. that fatigue strength increased with decreasing grain size, independent of short crack growth behavior.

\subsection{Effect of Heat Treatment on Fatigue Life Behavior}

Given that only subtle differences in short fatigue crack growth rates were observed for the three alloys and that fatigue lives in the VHCF range must then depend on differences in crack initiation lifetime, it is of interest to consider the role of microstructure on fatigue crack initiation behavior. In the present study both grain size and precipitate structure are modified by heat treatment. It is likely that crack initiation lifetime is affected by both precipitate structure and grain size, but quantifying the relative importance of each microstructural feature on fatigue crack initiation is difficult.

In the present study nanohardness measurements in the matrix, away from the influence of grain boundaries, support the hypothesis that differences in yield strength are due mainly to differences in precipitate structure produced in the different heat treatments. It must also be considered that remnant deformation may remain in the $\mathrm{T} 5$ condition that may also contribute to strengthening. Precipitation strengthening in WE43 occurs from the precipitation of a fine $\beta^{\prime}$ phase $[34,57]$. $\beta^{\prime}$ precipitates are more prevalent in the T5 condition than in the underaged or T6 conditions, which is consistent with the higher strength of the T5 condition [34]. The presence of strengthening precipitates in magnesium has also been shown to have a positive effect on stress-controlled HCF (S-N) fatigue resistance [21,58]. Further studies have shown that, although strengthening precipitates seem to have little effect on short crack growth behavior, consistent with the observation here, they can strongly affect fatigue strength by improving resistance to fatigue crack initiation [21,58]. In a study of an extruded Mg-10Gd-3Y alloy, Liu et al. found that short crack growth behavior was relatively unaffected by heat treatment, 
but that crack initiation was hindered by hardening effects from $\beta^{\prime}$ precipitates [58]. Similarly, in a study of aged AZ61 and AZ80, Uematsu et al. attributed increases in fatigue strength to changes in fatigue crack initiation mechanisms [21].

There is also evidence from the literature that grain size can affect crack initiation behavior. Uematsu et al. and Tsushida et al. have noted a grain size effect on fatigue behavior in magnesium alloys, with decreasing grain size leading to increased fatigue strength and fatigue lifetimes [24,59]. Li et al. noted a significant difference in fatigue strength, between two Mg$\mathrm{Nd}$ alloys of very similar composition and heat treatment, that was linked to a difference in deformation mechanisms in crack initiation resulting from different grain sizes [60]. In the present study crystallographic facets were associated with the initiation sites in both fine-grained T5 and coarse grained underaged and T6 conditions. These facets were in general larger than the average grain size (Figure 10), indicating that strain localization along favorably oriented slip planes is likely a precursor to fatigue crack initiation in WE43. In studies of the fatigue behavior of magnesium in the HCF and VHCF regimes, both Li et al. and Shiozawa et al. attributed crack initiation to cyclic slip deformation [17,60]. Cyclic slip is most likely to occur in grains that are both favorably oriented for slip and that maximize the mean free path for slip, i.e. largest possible diameter. Yue et al. have postulated that in initiation dominated fatigue coarse-grained materials perform poorly due to the ease of initiating cracks in larger grains [55]. This is attributed to an increase in the mean free path for slip, relative to finer-grained conditions. This means that Stage I fatigue cracks can grow more extensively into the specimen along crystallographic planes before encountering obstacles like grain boundaries or developing into Stage II cracks. The role of slip length and ease of crack initiation is further amplified by considering that in the fine-grained T5 condition, more than one similarly oriented facet was often observed at initiation sites, which is consistent with other studies in the VHCF regime where the proximity of multiple favorably oriented grains are the key microstructure feature associated with crack initiation $[14,61]$.

\subsubsection{Subsurface Crack Initiation}

In four of the low-stress VHCF fatigue life tests of the coarse-grained conditions, the fatal crack initiated at a subsurface location. However, the fatigue lives were not significantly different for samples that failed due to surface initiated cracks. In the specimens that exhibited subsurface initiation, crack initiation and propagation are presumably operating in a vacuum environment. It is well established that environment can have a strong effect on both fatigue crack initiation and crack propagation behavior [39,51,62-64]. The fracture surfaces at subsurface initiation sites were similar in appearance to fracture surfaces observed in small crack growth tests conducted in vacuum. 
Although environment has a clear effect on fatigue crack growth rate, it is unclear if environment plays a significant role in determining crack initiation mechanisms in WE43. Further study is necessary to determine the role of environment on fatigue crack initiation lives in WE43. Subsurface fatigue crack initiation in magnesium alloys has been linked to the presence of grains favorably oriented for slip, with crack initiation occurring through cyclic slip deformation to produce facets at initiation sites $[19,65]$. It has been noted before that generally as grain size increases, the ease of crack initiation also increases due to the increased mean free path for slip [55]. On average, facets located at subsurface initiation sites are approximately $20 \mu \mathrm{m}$ larger than those present at surface sites. Additionally, the average orientation of subsurface facets is more favorable for highly resolved shear stress, with an average inclination of $44^{\circ} \pm 10^{\circ}$ as compared to $34^{\circ} \pm 9^{\circ}$. It is expected that the occurrence of subsurface initiation is highly dependent on the microstructure of a given specimen. Given that a large average grain size and associated mean free path for slip favor crack initiation at both surface and subsurface locations, and that surface crack initiation is much more prevalent, it is likely that subsurface crack initiation can only occur when microstructural conditions for slip are optimized at subsurface locations, as in the observed initiation sites. Thus a probabilistic competition occurs between microstructural weak links, favored surface crack initiation at large grains that are oriented with moderate favorability for slip versus subsurface initiation at even larger grains that are better oriented for slip. The lack of subsurface crack initiation in the T5 condition is most likely due to the fine-grain structure. The grain size may be too small for subsurface slip to outpace surface crack initiation. Further study is necessary to understand this competition between surface initiation and subsurface initiation, as well as the role environment plays.

In this study, although we observed that fatigue crack growth rates were reduced by several orders of magnitude in vacuum, we also have concluded that crack propagation does not have a major influence on VHCF lifetimes, so this effect is presumably not significant for determining the lifetime of specimens with subsurface initiation sites. The observed differences in crack growth behavior between fatigue in vacuum and fatigue in laboratory air provided insight into the occurrence of subsurface crack initiation in WE43 magnesium. In this work, fatigue in vacuum resulted in crack growth rates one to two degrees of magnitude lower than crack growth rates observed in laboratory air. At comparable stress intensity levels, crack growth essentially halted in vacuum. Furthermore, following the change of environment, no transitional effect was observed in crack growth behavior or on the fracture surface. This indicates that material at the crack tip was immediately interacting with the environment, and that WE43 is highly susceptible to environmental effects. It has been observed in both conventional and ultrasonic fatigue that fatigue behavior in vacuum may vary significantly from that observed in laboratory air in many metals $[39,62,64]$. Stanzl-Tschegg et al. observed both higher crack growth rates and lower crack growth threshold in a humid air environment as compared to vacuum in a crack growth study of a 
2024-T3 aluminum alloy [62], and decreased crack growth rates in vacuum in a 7075-OA aluminum alloy and a Ti-6Al-4V alloy [64]. Geathers et al. observed an extreme effect of environment on short crack growth in Ti-6242S, with fatigue in vacuum essentially halting crack growth [39]. Studies of environmental effects on fatigue crack growth in magnesium alloys are limited. Tokaji et al. observed a significant decrease in crack propagation rates in dry air as opposed to laboratory air in magnesium alloys AZ31 and AZ61 [66]. Similar trends were reported in a study of AZ61 cycling in dry air and in a range of relative humidities [67]. Studies of steels [68,69], Superalloys [70], and titanium alloys [13] have shown that generally reduced fatigue lives for surface initiated cracks as compared to subsurface initiated cracks are due to the acceleration of surface crack initiation and growth by a laboratory air environment as compared to quasi-vacuum conditions in the interior of the specimen.

The question of environment assisted fatigue crack growth in magnesium alloys in the VHCF regime is an interesting one that merits further study. Additional research using the UFSEM system in combination with a Quanta Environmental SEM is underway to more fully investigate this question for a variety of gaseous environments.

\section{Conclusions}

Axial ultrasonic fatigue tests have been performed on smooth, cylindrical specimens of a hot-rolled WE43 magnesium alloy in laboratory air at ambient temperature using ultrasonic fatigue equipment. The effect of heat treatment on fatigue strength in the very high cycle regime has been discussed in terms of short crack growth and fatigue crack initiation behavior in the T5, underaged, and T6 conditions. Subsurface fatigue crack initiation in underaged and T6 WE43 was investigated. The following conclusions can be made:

- Heat treatment had a significant effect on fatigue strengths at $10^{9}$ cycles for the $\mathrm{T} 5$, underaged, and $\mathrm{T} 6$ conditions, with values of $110 \mathrm{MPa}, 65 \mathrm{MPa}$, and $65 \mathrm{MPa}$, respectively. The dramatic difference in fatigue strength correlated with differences in tensile properties and hardness derived from nanoindentation experiments.

- Crack initiation sites exhibited evidence of cyclic strain accumulation as a crack initiation mechanism. Crack initiation sites in each of the three conditions featured large facets oriented for high resolved shear stress.

- Heat treatment had no significant effect on average crack growth rates. Despite local variations in short crack growth rate, average crack growth rates for each of the three conditions were very similar at stress intensities greater than $1.5 \mathrm{MPa} \cdot \mathrm{m}^{1 / 2}$.

- Crack paths in each of the conditions were strongly affected by local microstructure, with cracks predominantly propagating in a crystallographic transgranular manner. Crack path deflection was observed at grain boundaries in 
each condition, with larger departures from the generalized crack plane observed in the coarse-grained conditions as a result of the larger average grain size.

- It appears that fatigue lives in the VHCF regime are primarily determined by the number of cycles to initiate a grain size crack. Small fatigue crack growth appears to have no significant effect on fatigue lives in this regime.

\section{Acknowledgements}

This work was supported by the U.S. Department of Energy, Office of Basic Energy Sciences, Division of Materials Sciences and Engineering under Award \#DE-SC0008637 as part of the Center for PRedictive Integrated Structural Materials Science (PRISMS Center) at University of Michigan. We thank Bruce Davis of Magnesium Elektron for providing the alloy for this research.

\section{References}

[1] Cole GS. Issues that Influence Magnesium's Use in the Automotive Industry. Mater Sci Forum 2003;419-422:4350. doi:10.4028/www.scientific.net/MSF.419-422.43.

[2] Bathias C, Paris PC. Gigacycle Fatigue in Mechanical Practice. New York: Marcel Dekker; 2005.

[3] Stanzl-Tschegg S. Very high cycle fatigue measuring techniques. Int J Fatigue 2014;60:2-17. doi:10.1016/j.ijfatigue.2012.11.016.

[4] Mayer H. Recent developments in ultrasonic fatigue. Fatigue Fract Eng Mater Struct 2016;39:3-29. doi:10.1111/ffe. 12365 .

[5] Nascimento L, Yi S, Bohlen J, Fuskova L, Letzig D, Kainer KU. High cycle fatigue behaviour of magnesium alloys. Procedia Eng 2010;2:743-50. doi:10.1016/j.proeng.2010.03.080.

[6] Zhu X, Jones JW, Allison JE. Effect of frequency, environment, and temperature on fatigue behavior of E319 cast aluminum alloy: Stress-controlled fatigue life response. Metall Mater Trans A 2008;39A:2681-8. doi:10.1007/s11661-008-9631-1.

[7] Miao J, Pollock TM, Wayne Jones J. Crystallographic fatigue crack initiation in nickel-based superalloy René 88DT at elevated temperature. Acta Mater 2009;57:5964-74. doi:10.1016/j.actamat.2009.08.022.

[8] Stanzl-Tschegg S, Mughrabi H, Schoenbauer B. Life time and cyclic slip of copper in the VHCF regime. Int J Fatigue 2007;29:2050-9. doi:10.1016/j.ijfatigue.2007.03.010.

[9] Lukáš P, Kunz L. Specific features of high-cycle and ultra-high-cycle fatigue. Fatigue Fract Eng Mater Struct 2002;25:747-53. doi:10.1046/j.1460-2695.2002.00562.x.

[10] Atrens A, Hoffelner W, Duerig TW, Allison JE. Subsurface Crack Initiation in High Cycle Fatigue in Ti6Al4V and in a Typical Martensitic Stainless Steel. Scr Metall 1983;17:601-6.

[11] Mughrabi H. On the life-controlling microstructural fatigue mechanisms in ductile metals and alloys in the gigacycle regime. Fatigue Fract Eng Mater Struct 1999;22:633-41. doi:10.1046/j.1460-2695.1999.00186.x.

[12] Wang QY, Bathias C, Kawagoishi N, Chen Q. Effect of inclusion on subsurface crack initiation and gigacycle fatigue strength. Int Jounal Fatigue 2002;24:1269-74.

[13] Ravi Chandran KS, Jha SK. Duality of the S-N fatigue curve caused by competing failure modes in a titanium alloy 
and the role of Poisson defect statistics. Acta Mater 2005;53:1867-81. doi:10.1016/j.actamat.2004.12.032.

[14] Szczepanski CJ, Jha SK, Larsen JM, Jones JW. Microstructural Influences on Very-High-Cycle Fatigue-Crack Initiation in Ti-6246. Metall Mater Trans A 2008;39:2841-51. doi:10.1007/s11661-008-9633-z.

[15] Huang Z, Wagner D, Bathias C, Paris PC. Subsurface crack initiation and propagation mechanisms in gigacycle fatigue. Acta Mater 2010;58:6046-54. doi:10.1016/j.actamat.2010.07.022.

[16] Stanzl-Tschegg SE, Schönbauer B. Mechanisms of strain localization, crack initiation and fracture of polycrystalline copper in the VHCF regime. Int J Fatigue 2010;32:886-93. doi:10.1016/j.ijfatigue.2009.03.016.

[17] Shiozawa K, Kashiwagi T, Murai T, Takahashi T. Fatigue behaviour and fractography of extruded AZ80 magnesium alloys in very high cycle regime. Procedia Eng 2010;2:183-91. doi:10.1016/j.proeng.2010.03.020.

[18] Xu DK, Liu L, Xu YB, Han EH. The crack initiation mechanism of the forged $\mathrm{Mg}-\mathrm{Zn}-\mathrm{Y}-\mathrm{Zr}$ alloy in the superlong fatigue life regime. Scr Mater 2007;56:1-4. doi:10.1016/j.scriptamat.2006.09.006.

[19] Tokaji K, Kamakura M, Ishiizumi Y, Hasegawa N. Fatigue behaviour and fracture mechanism of a rolled AZ31 magnesium alloy. Int J Fatigue 2004;26:1217-24. doi:10.1016/j.ijfatigue.2004.03.015.

[20] Uematsu Y, Kakiuchi T, Tamada K, Kamiya Y. EBSD analysis of fatigue crack initiation behavior in coarsegrained AZ31 magnesium alloy. Int J Fatigue 2016;84:1-8. doi:10.1016/j.ijfatigue.2015.11.010.

[21] Uematsu Y, Tokaji K, Matsumoto M. Effect of aging treatment on fatigue behaviour in extruded AZ61 and AZ80 magnesium alloys. Mater Sci Eng A 2009;517:138-45. doi:10.1016/j.msea.2009.03.066.

[22] Zhang B, Poirier DR, Chen W. Microstructural effects on high-cycle fatigue-crack initiation in A356.2 casting alloy. Metall Mater Trans A 1999;30A:2659-66. doi:10.1007/s11661-999-0306-3.

[23] Ishihara S, Namito T, Yoshifuji S, Goshima T. On fatigue lives of diecast and extruded Mg alloys. Int J Fatigue 2012;35:56-62. doi:10.1016/j.ijfatigue.2010.11.023.

[24] Uematsu Y, Tokaji K, Kamakura M, Uchida K, Shibata H, Bekku N. Effect of extrusion conditions on grain refinement and fatigue behaviour in magnesium alloys. Mater Sci Eng A 2006;434:131-40. doi:10.1016/j.msea.2006.06.117.

[25] Bernard JD, Jordon JB, Horstemeyer MF, Kadiri HE, Baird J, Lamb D, et al. Structure-property relations of cyclic damage in a wrought magnesium alloy. Scr Mater 2010;63:751-6. doi:10.1016/j.scriptamat.2010.05.048.

[26] Yu Q, Zhang J, Jiang Y. Fatigue damage development in pure polycrystalline magnesium under cyclic tensioncompression loading. Mater Sci Eng A 2011;528:7816-26. doi:10.1016/j.msea.2011.06.064.

[27] Zeng R, Han E, Ke W, Dietzel W, Kainer KU, Atrens A. Influence of microstructure on tensile properties and fatigue crack growth in extruded magnesium alloy AM60. Int J Fatigue 2010;32:411-9. doi:10.1016/j.ijfatigue.2009.07.021.

[28] Ishihara S, Nan Z, Goshima T. Effect of microstructure on fatigue behavior of AZ31 magnesium alloy. Mater Sci Eng A 2007;468-470:214-22. doi:10.1016/j.msea.2006.09.124.

[29] Sajuri Z Bin, Miyashita Y, Hosokai Y, Mutoh Y. Effects of Mn content and texture on fatigue properties of as-cast and extruded AZ61 magnesium alloys. Int J Mech Sci 2006;48:198-209. doi:10.1016/j.ijmecsci.2005.09.003.

[30] Agnew SR. Wrought magnesium: A 21st century outlook. Jom 2004;56:20-1. doi:10.1007/s11837-004-0120-8.

[31] King A, Ludwig W, Herbig M, Buffière J-Y, Khan AA, Stevens N, et al. Three-dimensional in situ observations of short fatigue crack growth in magnesium. Acta Mater 2011;59:6761-71. doi:10.1016/j.actamat.2011.07.034.

[32] Nicoletto G, Konečná R, Pirondi A. Fatigue crack paths in coarse-grained magnesium. Fatigue Fract Eng Mater Struct 2005;28:237-44. doi:10.1111/j.1460-2695.2004.00832.x.

[33] Zheng S, Yu Q, Jiang Y. An experimental study of fatigue crack propagation in extruded AZ31B magnesium alloy. 
Int J Fatigue 2013;47:174-83. doi:10.1016/j.ijfatigue.2012.08.010.

[34] Solomon E, Marquis E. Private Communication 2016.

[35] Githens AS. Deformation Mechanisms of Magnesium Alloy WE43 under Monotonic Tensile Loading. University of Michigan, 2015.

[36] Wang YN, Huang JC. Texture analysis in hexagonal materials. Mater Chem Phys 2003;81:11-26. doi:10.1016/S0254-0584(03)00168-8.

[37] Mayer H. Fatigue crack growth and threshold measurements at very high frequencies. Int Mater Rev 1999;44:1-34. doi:10.1179/095066099771048801.

[38] Liu L, Husseini NS, Torbet CJ, Kumah DP, Clarke R, Pollock TM, et al. In Situ Imaging of High Cycle Fatigue Crack Growth in Single Crystal Nickel-Base Superalloys by Synchrotron X-Radiation. J Eng Mater Technol 2008;130:021008. doi:10.1115/1.2840966.

[39] Geathers J, Torbet CJ, Jones JW, Daly S. Investigating environmental effects on small fatigue crack growth in Ti6242S using combined ultrasonic fatigue and scanning electron microscopy. Int J Fatigue 2015;70:154-62. doi:10.1016/j.ijfatigue.2014.09.007.

[40] Newman JC, Raju IS. NASA Technical Memorandum 85793: Stress-Intensity Factor Equations for Cracks in Three-Dimensional Finite Bodies Subjected to Tension and Bending Loads. 1984.

[41] ASTM Standard E647 - 13a. Standard Test Method for Measurement of Fatigue Crack Growth Rates. Am Soc Test Mater 2014:1-50. doi:10.1520/E0647-13A.2.

[42] Themelis G, Chikwembani S, Weertman J. Determination of the orientation of CuBi grain boundary facets using a photogrammetric technique. Mater Charact 1990;24:27-40. doi:10.1016/1044-5803(90)90069-V.

[43] Ogarevic V V., Stephens RI. Fatigue of Magnesium Alloys. Annu Rev Mater Sci 1990;20:141-77.

[44] Spear AD, Li SF, Lind JF, Suter RM, Ingraffea AR. Three-dimensional characterization of microstructurally small fatigue-crack evolution using quantitative fractography combined with post-mortem X-ray tomography and highenergy X-ray diffraction microscopy. Acta Mater 2014;76:413-24. doi:10.1016/j.actamat.2014.05.021.

[45] McFadyen N, Bell R, Vosikovsky O. Fatigue crack growth of semi-elliptical surface cracks. Int J Fatigue 1990;12:43-50. doi:10.1016/0142-1123(90)90341-B.

[46] Darvish M, Johansson S. BEACH MARK FORMATION CAUSED BY CHANGES IN ENVIRONMENTAL HUMIDITY DURING FATIGUE 1995;18:319-27.

[47] Burns JT, Larsen JM, Gangloff RP. Effect of initiation feature on microstructure-scale fatigue crack propagation in Al-Zn-Mg-Cu. Int J Fatigue 2012;42:104-21. doi:10.1016/j.ijfatigue.2011.08.001.

[48] Branco R, Antunes F V., Costa JD, Yang FP, Kuang ZB. Determination of the Paris law constants in round bars from beach marks on fracture surfaces. Eng Fract Mech 2012;96:96-106. doi:10.1016/j.engfracmech.2012.07.009.

[49] Bieler TR, Eisenlohr P, Zhang C, Phukan HJ, Crimp MA. Grain boundaries and interfaces in slip transfer. Curr Opin Solid State Mater Sci 2014;18:212-26. doi:10.1016/j.cossms.2014.05.003.

[50] Zhai T, Wilkinson AJ, Martin JW. Crystallographic mechanism for fatigue crack propagation through grain boundaries. Acta Mater 2000;48:4917-27. doi:10.1016/S1359-6454(00)00214-7.

[51] Gall K, Biallas G, Maier HJ, Horstemeyer MF, McDowell DL. Environmentally influenced microstructurally small fatigue crack growth in cast magnesium. Mater Sci Eng A 2005;396:143-54. doi:10.1016/j.msea.2005.01.014.

[52] Ravichandran KS. A theoretical model for roughness induced crack closure. Int J Fract 1990;44:97-110. doi:10.1007/BF00047062.

[53] Zurek AK, James MR, Morris WL. The effect of grain size on fatigue growth of short cracks. Metall Trans A 
1983;14A:1697-705.

[54] Turnbull A, de los Rios ER. the Effect of Grain Size on Fatigue Crack Growth in an Aluminium Magnesium Alloy. Fatigue Fract Eng Mater Struct 1995;18:1355-66. doi:10.1111/j.1460-2695.1995.tb00861.x.

[55] Yue TM, Ha HU, Musson NJ. Grain size effects on the mechanical properties of some squeeze cast light alloys. J Mater Sci 1995;30:2277-83. doi:10.1007/BF01184573.

[56] Horstemeyer MF, Yang N, Gall K, McDowell DL, Fan J, Gullett PM. High cycle fatigue of a die cast AZ91E-T4 magnesium alloy. Acta Mater 2004;52:1327-36. doi:10.1016/j.actamat.2003.11.018.

[57] Nie J-F. Precipitation and Hardening in Magnesium Alloys. Metall Mater Trans A 2012;43:3891-939. doi:10.1007/s11661-012-1217-2.

[58] Liu W-C, Dong J, Zhang P, Jin L, Peng T, Zhai C-Q, et al. Fatigue behavior of hot-extruded Mg-10Gd-3Y magnesium alloy. J Mater Res 2010;25:773-83. doi:10.1557/JMR.2010.0104.

[59] Tsushida M, Shikada K, Kitahara H, Ando S, Tonda H. Relationship between Fatigue Strength and Grain Size in AZ31 Magnesium Alloys. Mater Trans 2008;49:1157-61. doi:10.2320/matertrans.MC2007101.

[60] Li Z, Wang Q, Luo AA, Zhang P, Peng L. Size Effect on Magnesium Alloy Castings. Metall Mater Trans A 2016;47A:2686-704. doi:10.1007/s11661-016-3436-4.

[61] Miao J, Pollock TM, Wayne Jones J. Microstructural extremes and the transition from fatigue crack initiation to small crack growth in a polycrystalline nickel-base superalloy. Acta Mater 2012;60:2840-54. doi:10.1016/j.actamat.2012.01.049.

[62] Stanzl SE, Mayer HR, Tschegg EK. The influence of air humidity on near-threshold fatigue crack growth of 2024T3 aluminum alloy. Mater Sci Eng A 1991;147:45-54. doi:10.1016/0921-5093(91)90803-U.

[63] Sajuri ZB, Miyashita Y, Mutoh Y. Effects of humidity and temperature on the fatigue behaviour of an extruded AZ61 magnesium alloy. Fatigue Fract Eng Mater Struct 2005;28:373-9. doi:10.1111/j.1460-2695.2005.00775.x.

[64] Stanzl-tschegg S. International Journalof Fatigue Fatigue crack growth and thresholds at ultrasonic frequencies. Int Jounal Fatigue 2006;28:1456-64. doi:10.1016/j.ijfatigue.2005.06.058.

[65] Gall K, Biallas G, Maier HJ, Gullett P, Horstemeyer MF, McDowell DL, et al. In-situ observations of high cycle fatigue mechanisms in cast AM60B magnesium in vacuum and water vapor environments. Int J Fatigue 2004;26:59-70. doi:10.1016/S0142-1123(03)00079-3.

[66] Tokaji K, Nakajima M, Uematsu Y. Fatigue crack propagation and fracture mechanisms of wrought magnesium alloys in different environments. Int J Fatigue 2009;31:1137-43. doi:10.1016/j.ijfatigue.2008.12.012.

[67] Uematsu Y, Kakiuchi T, Nakajima M, Nakamura Y, Miyazaki S, Makino H. Fatigue crack propagation of AZ61 magnesium alloy under controlled humidity and visualization of hydrogen diffusion along the crack wake. Int $\mathbf{J}$ Fatigue 2014;59:234-43. doi:10.1016/j.ijfatigue.2013.08.014.

[68] Murakami Y, Yokoyama NN, Nagata J. Mechanism of fatigue failure in ultralong life regime. Fatigue Fract Eng Mater Struct 2002;25:735-46. doi:10.1046/j.1460-2695.2002.00576.x.

[69] Shiozawa K, Lu L. Very high-cycle fatigue behaviour of shot-peened high-carbon-chromium bearing steel. Fatigue Fract Eng Mater Struct 2002;25:813-22. doi:10.1046/j.1460-2695.2002.00567.x.

[70] Shamblen CE, Chang DR. Effect of inclusions on LCF life of HIP plus heat treated powder metal rené 95. Metall Trans B 1985;16:775-84. doi:10.1007/BF02667513. 


\section{Figure 1 - Double Column}
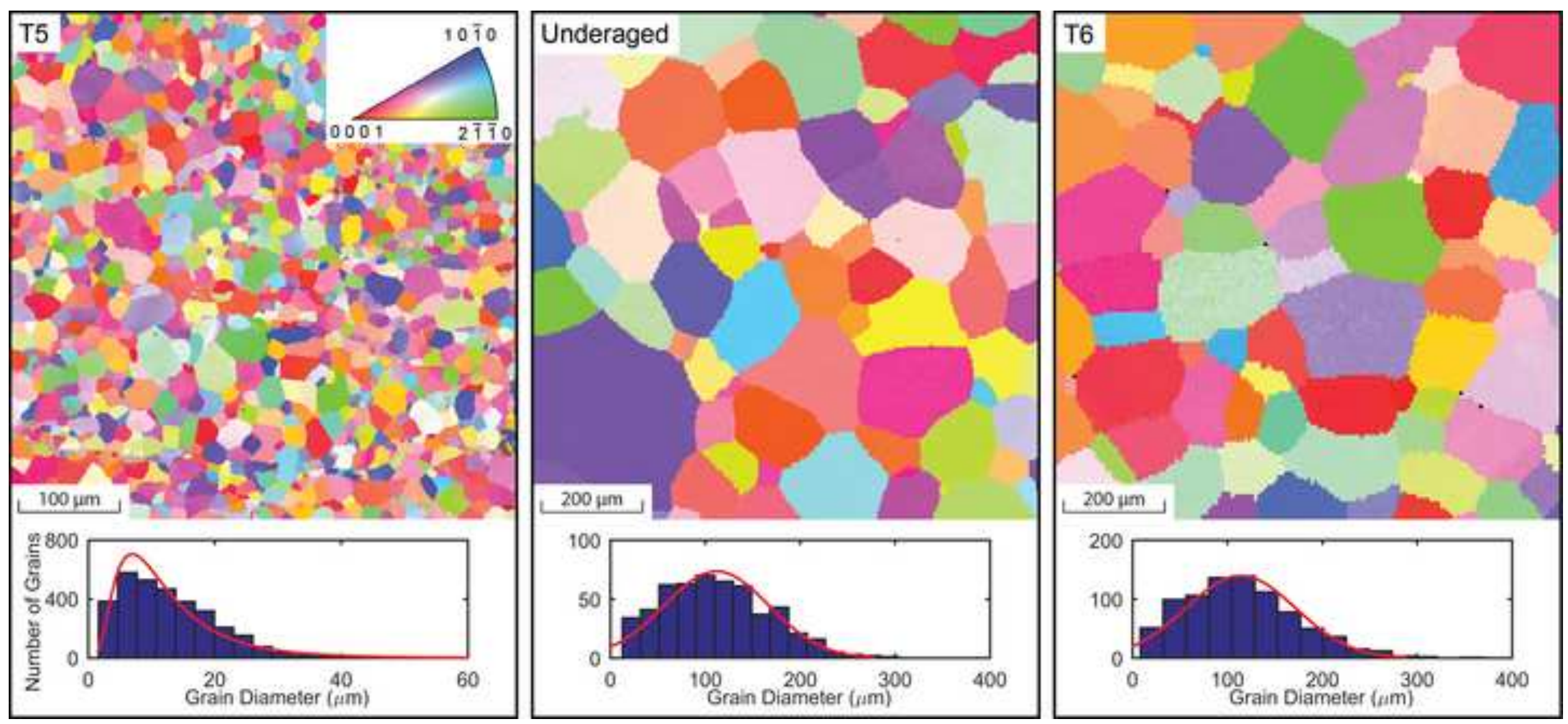

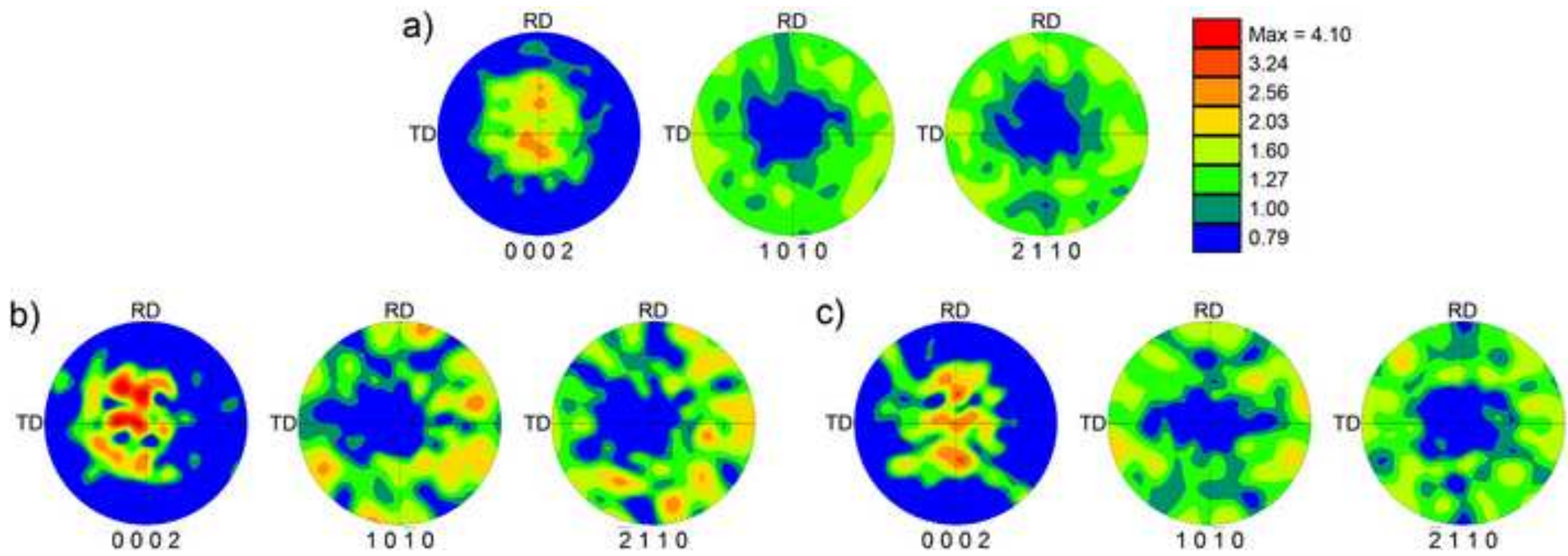


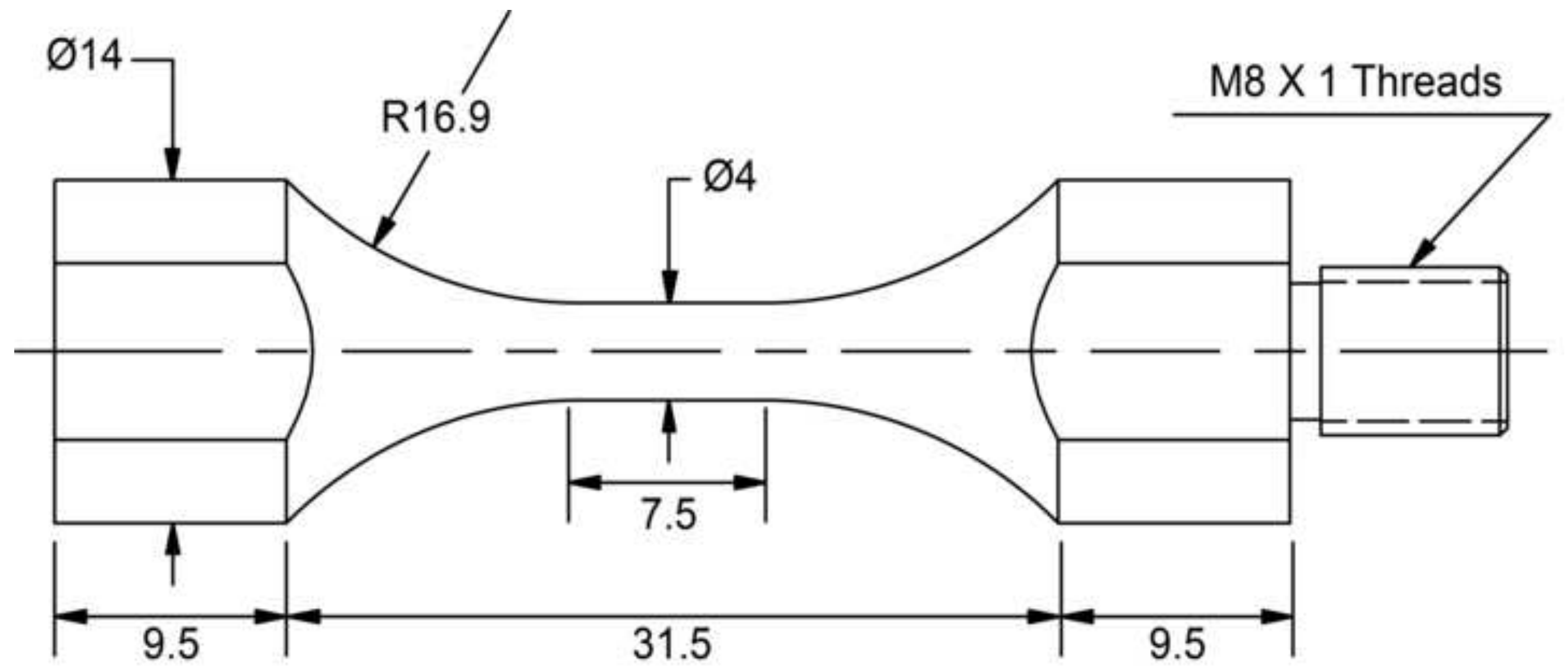

All units in $\mathrm{mm}$ 


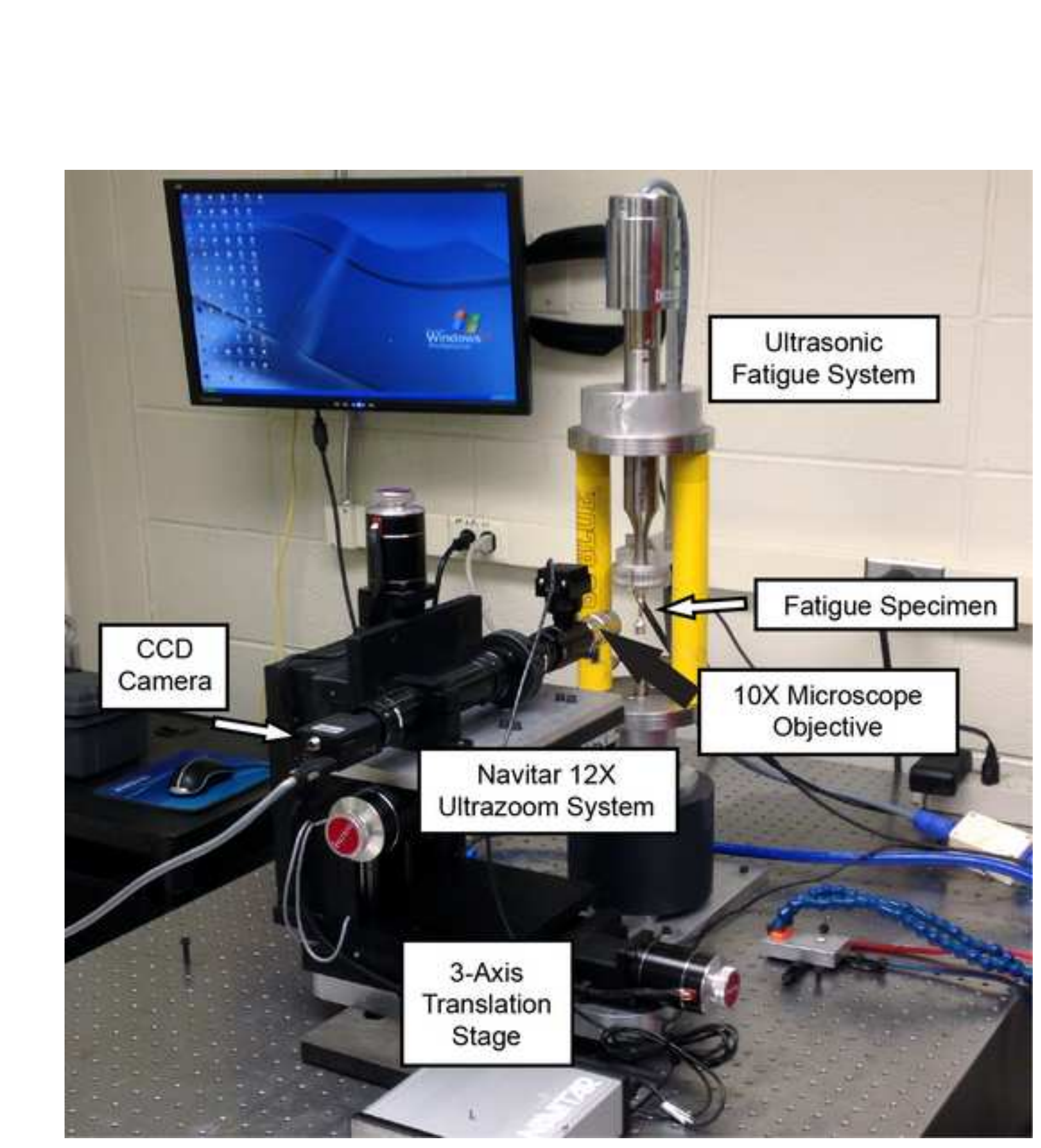

Figure 4 - Single Column

\section{Fatigue System}
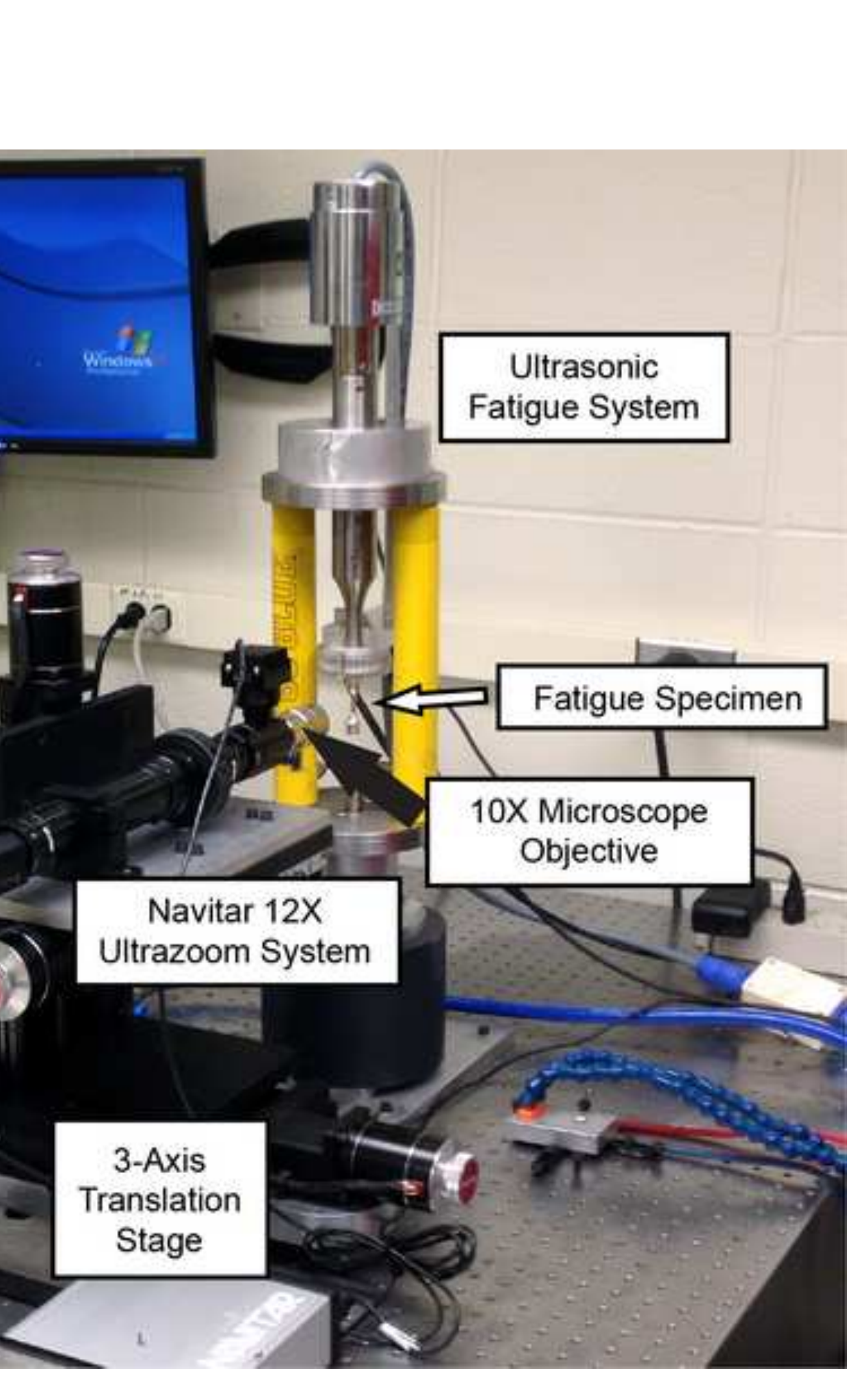


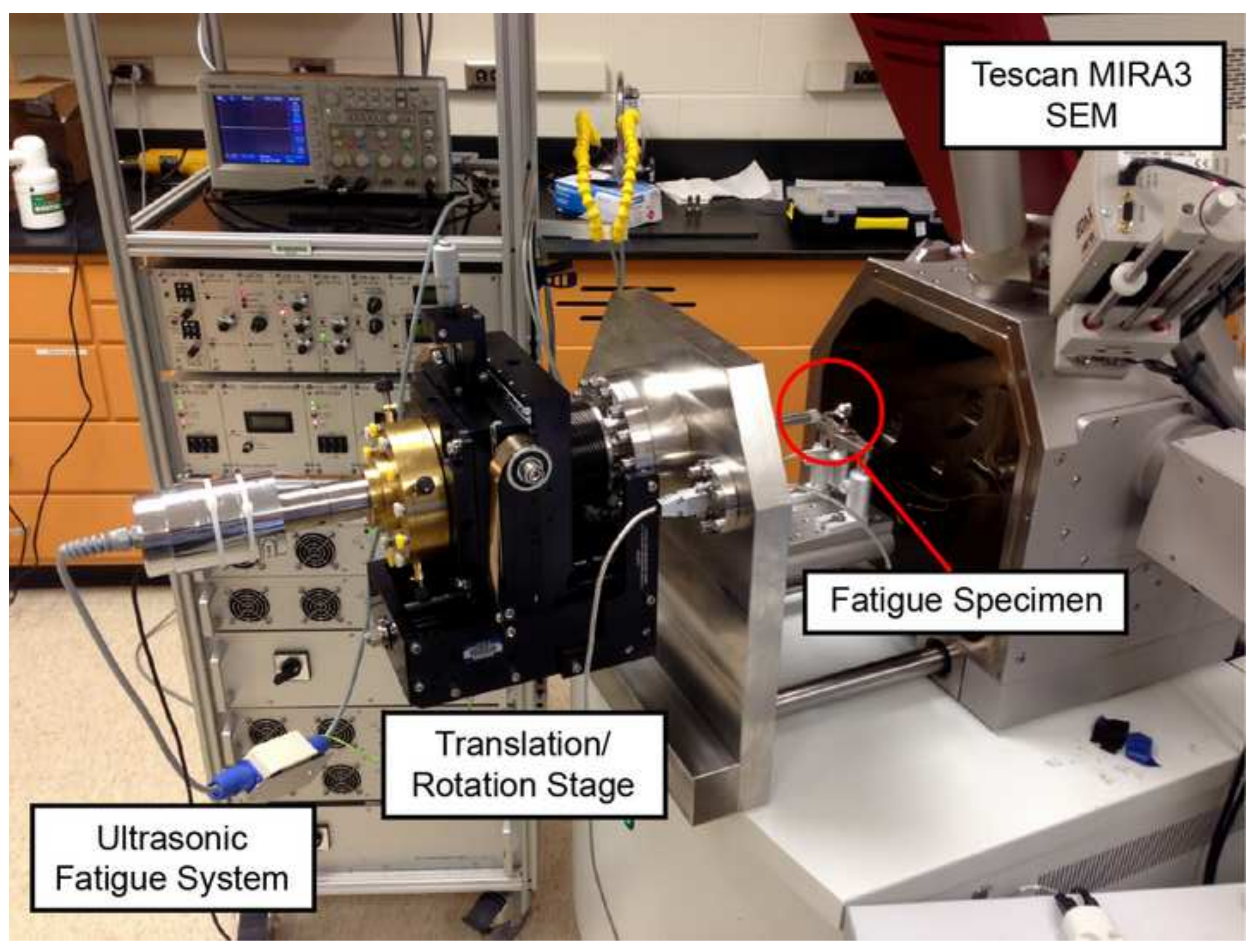




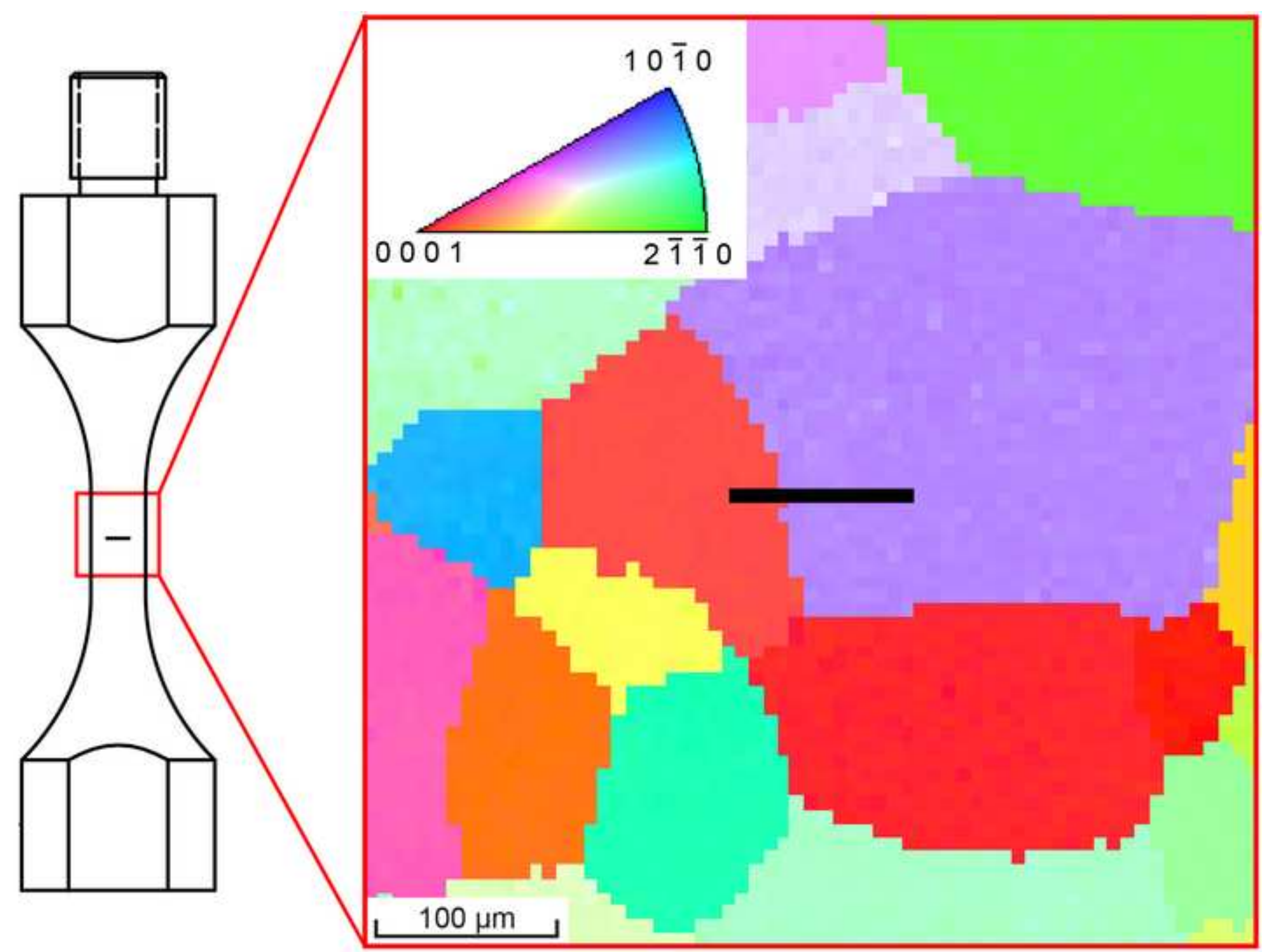




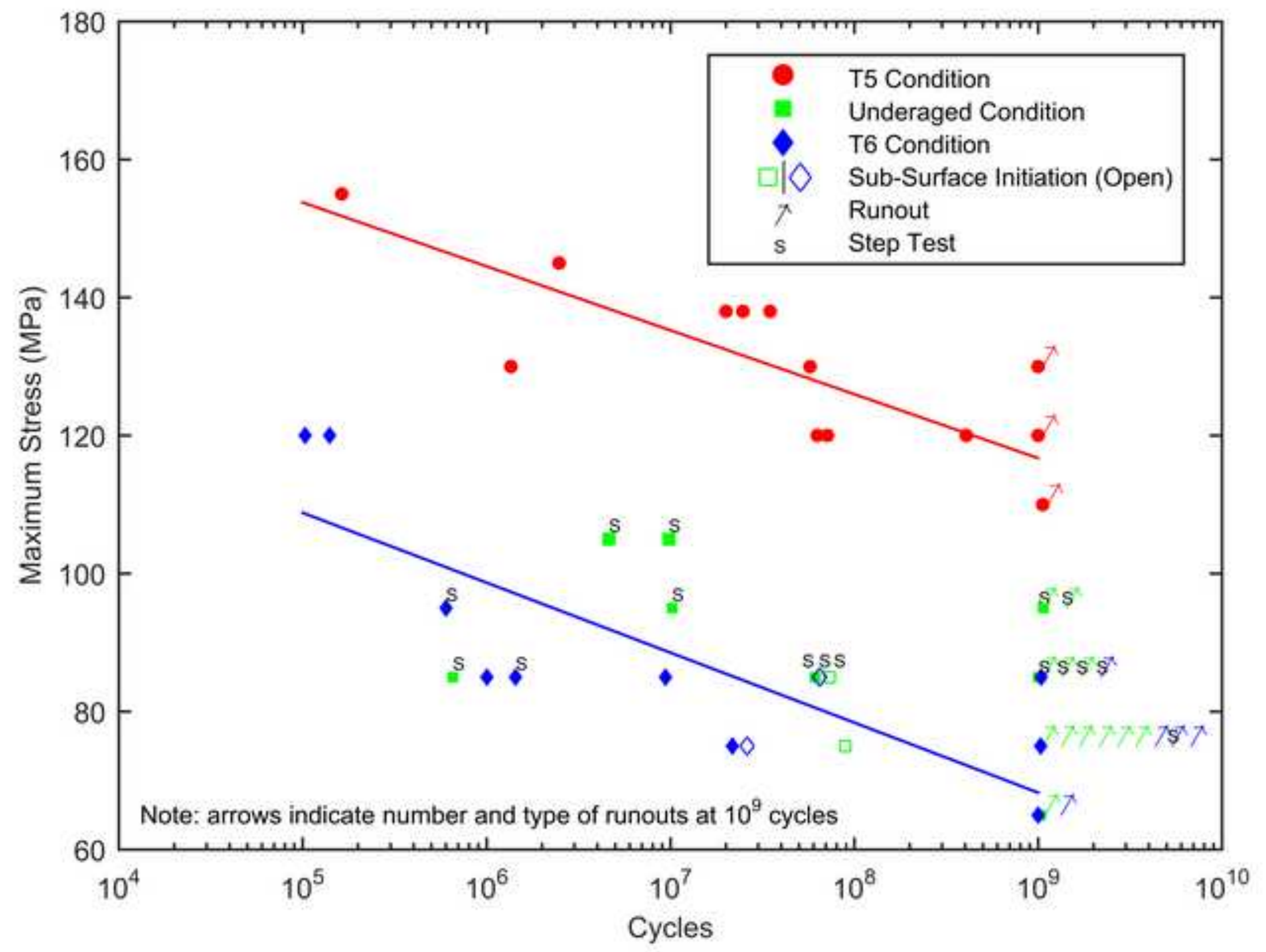



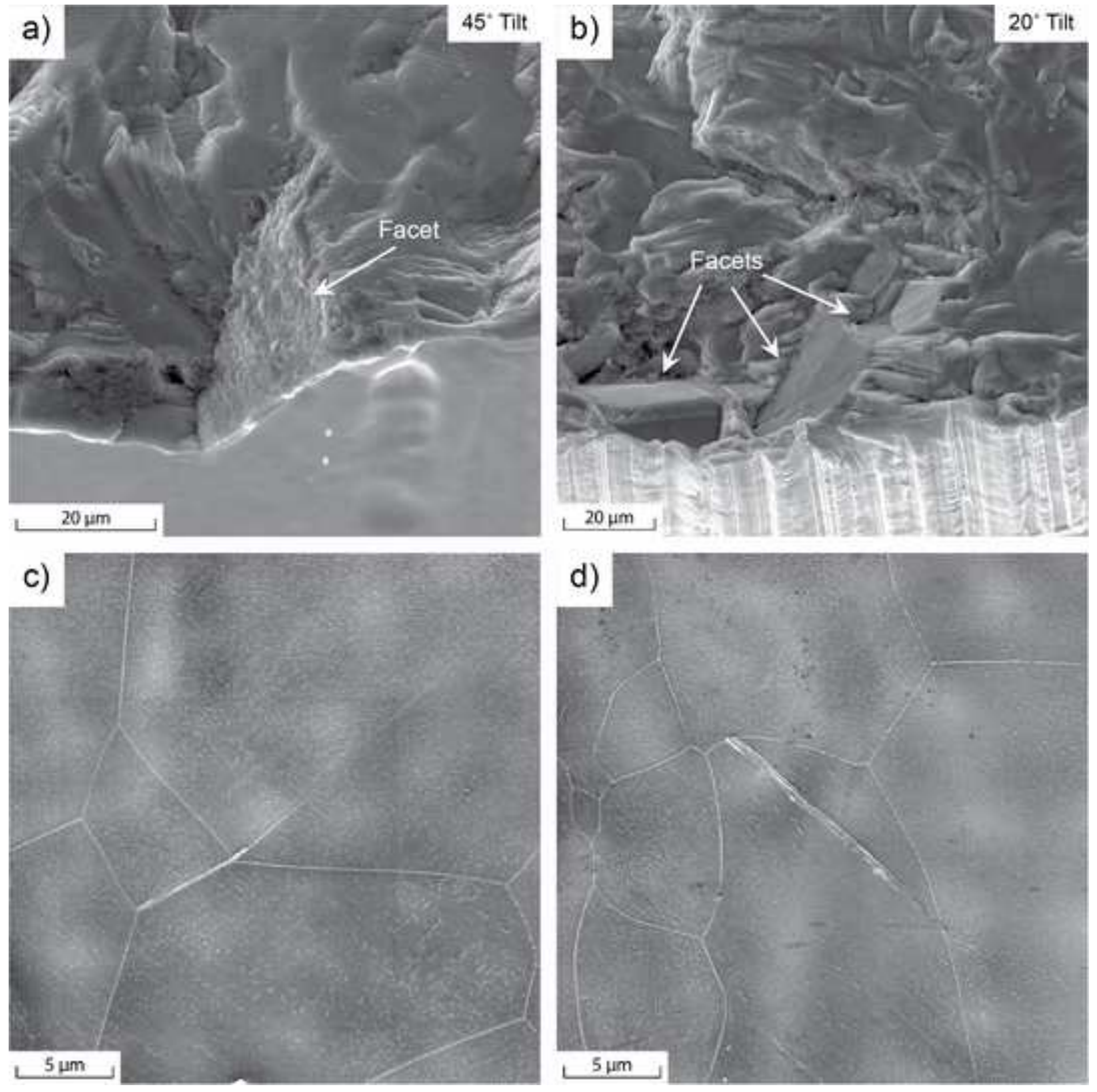


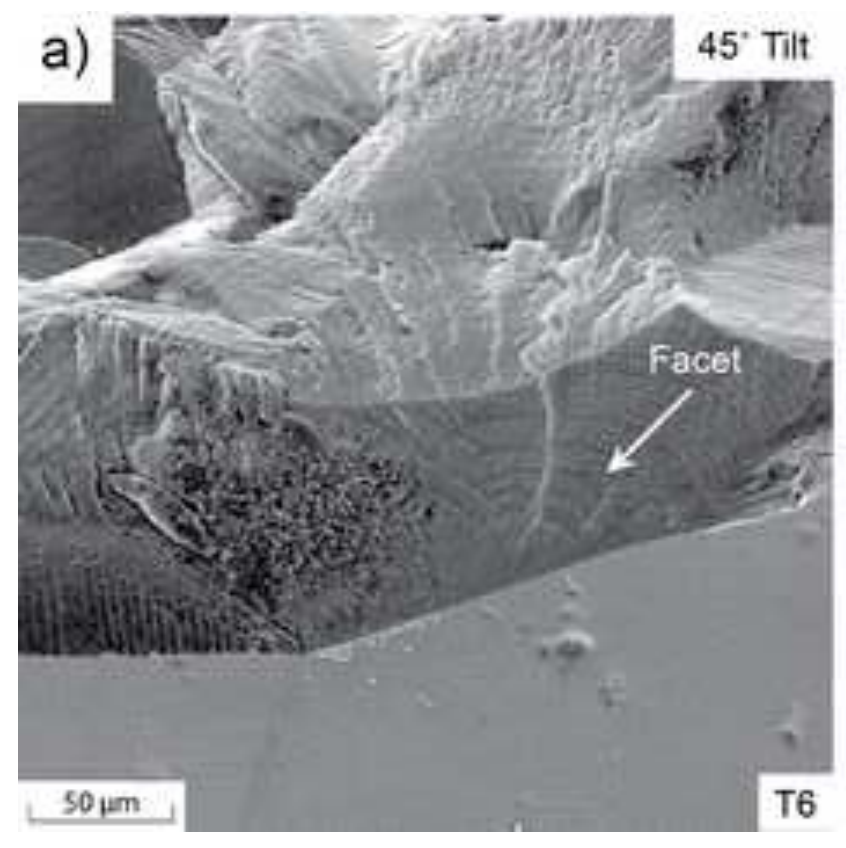

b)

soum

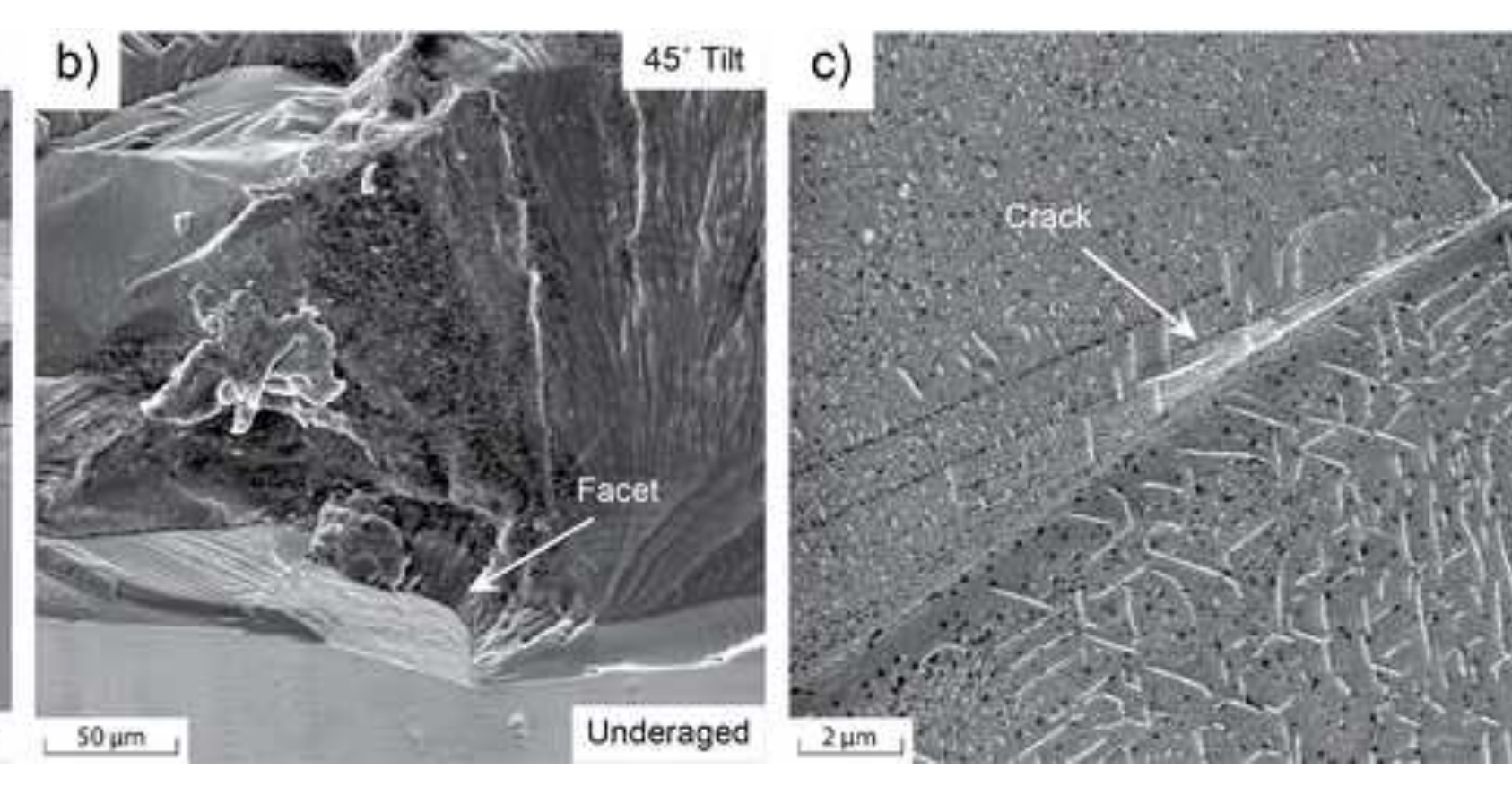

c)

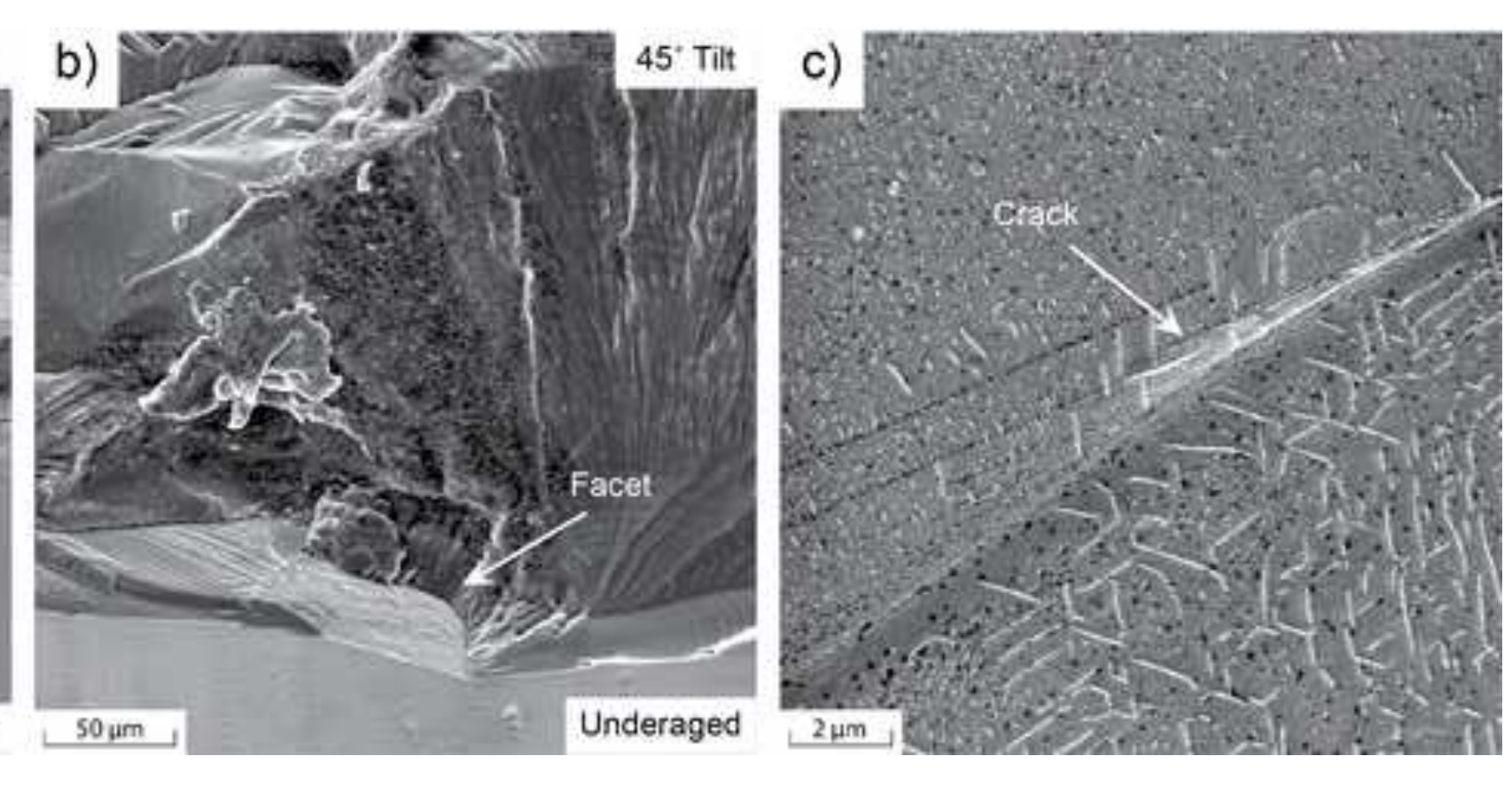

.

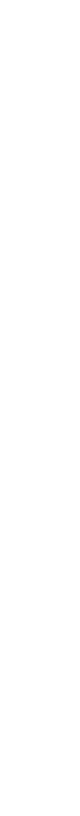



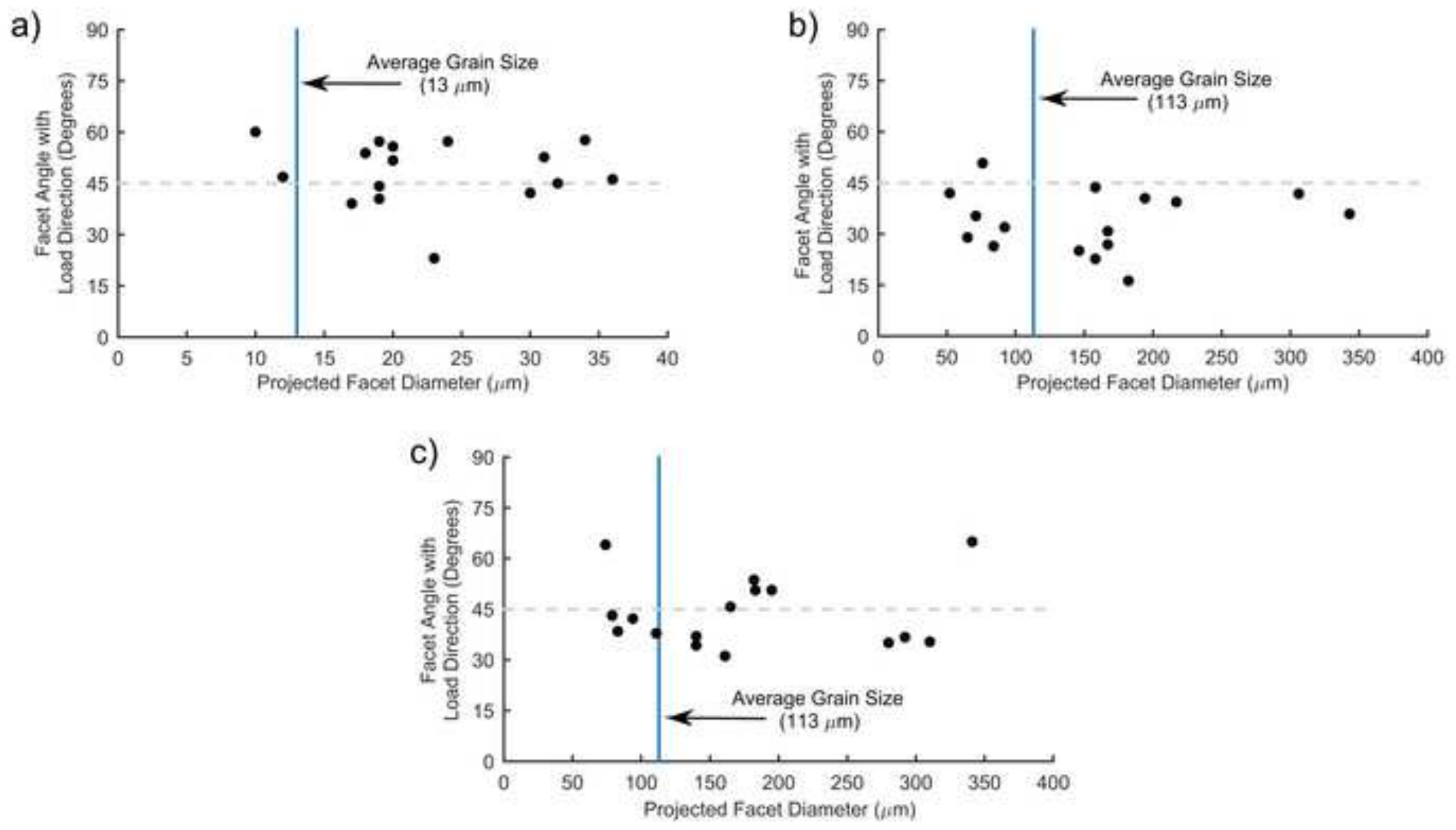

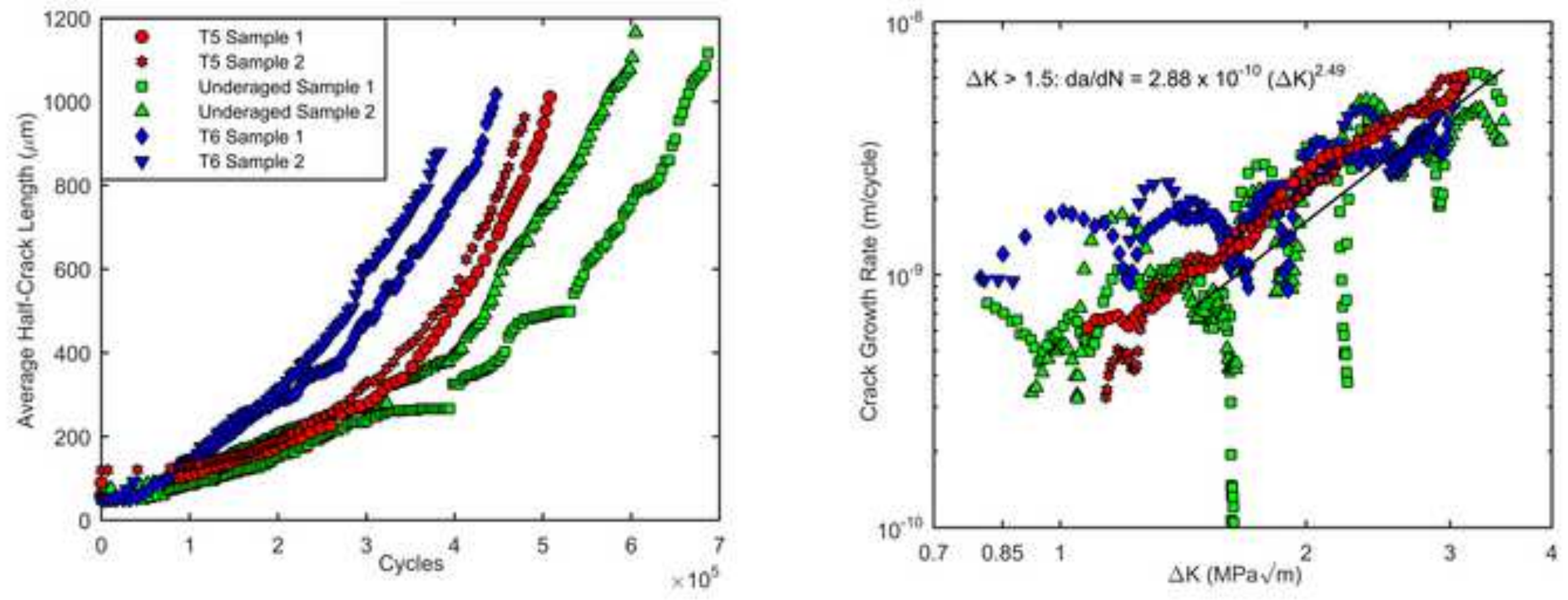

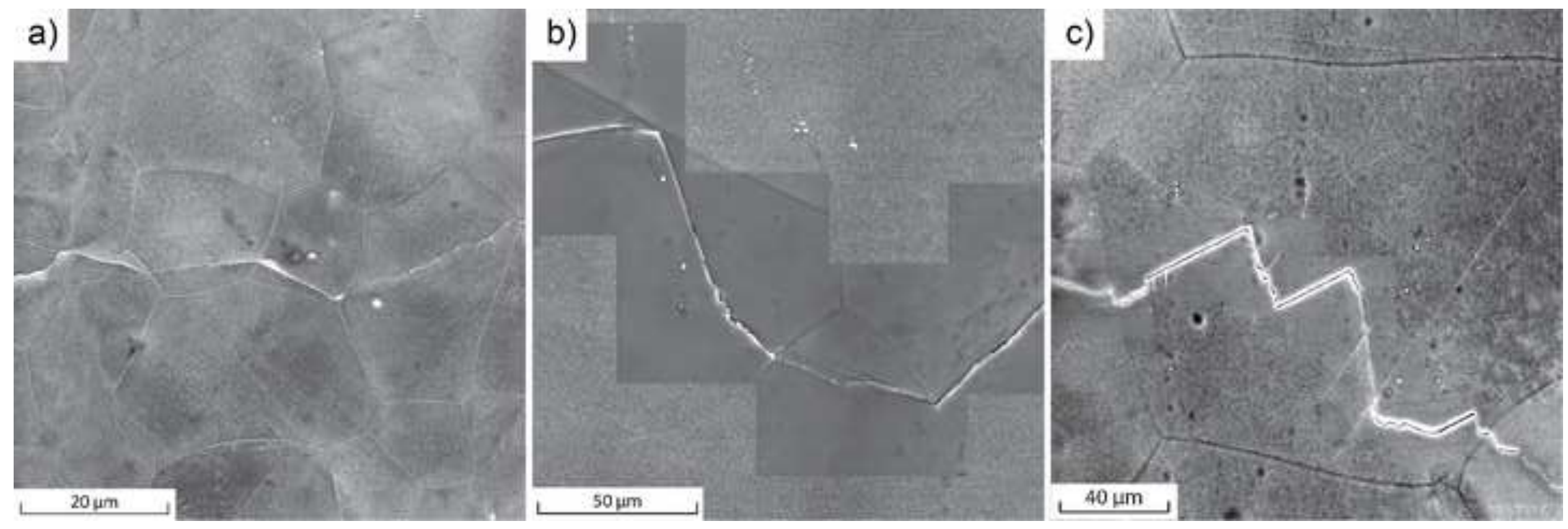

Figure 13 - Double Column 

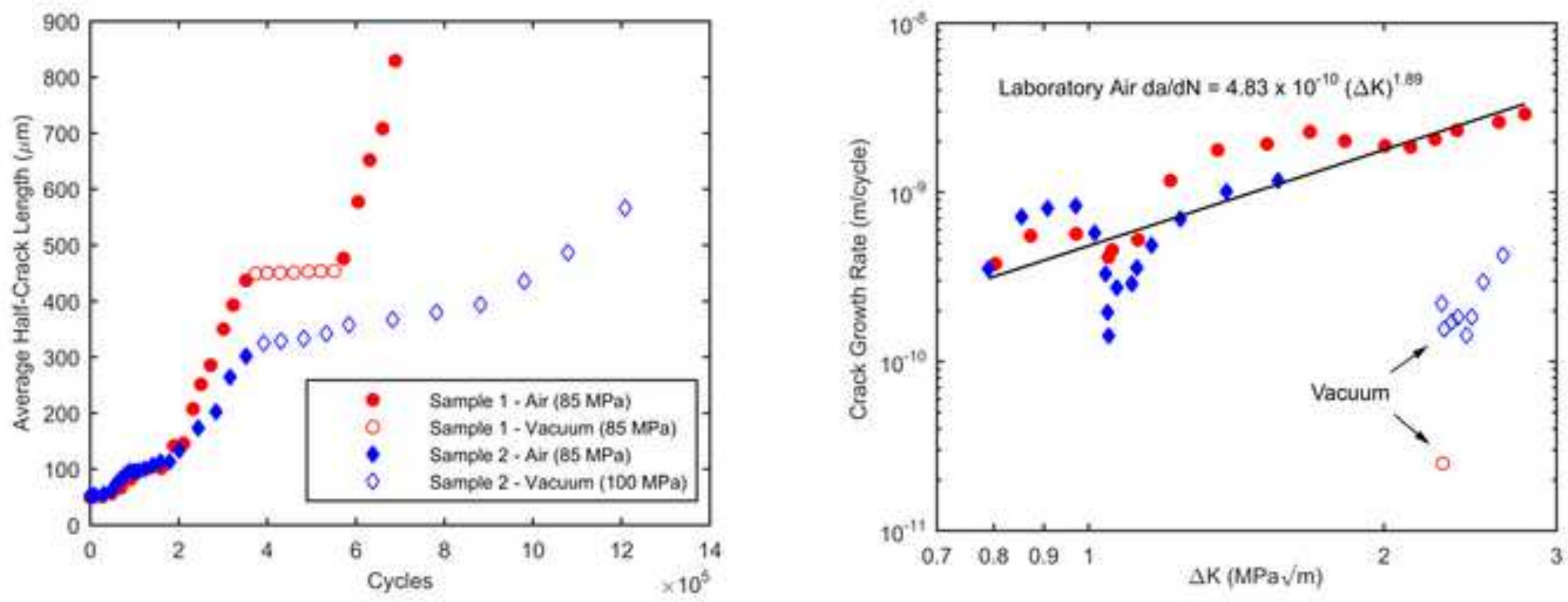
a)

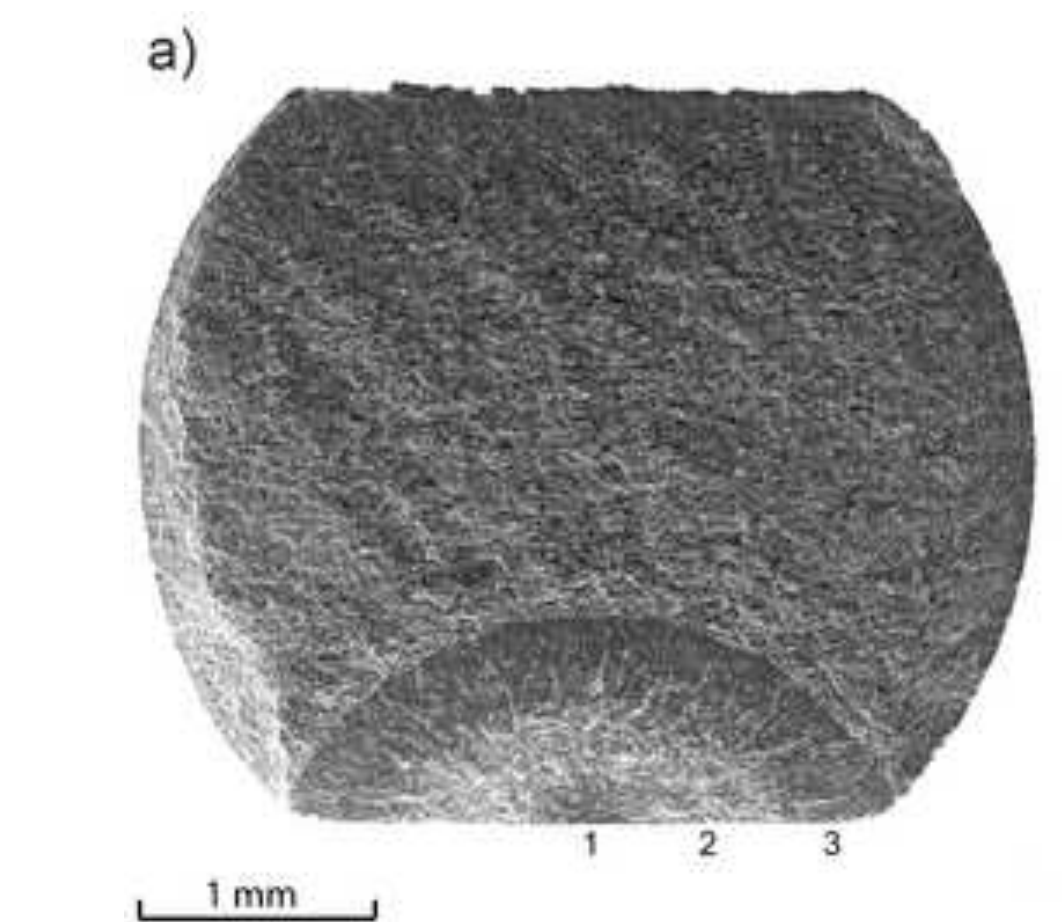

$1 \mathrm{~mm}$

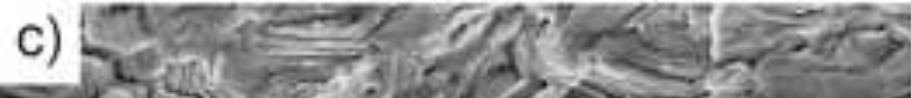

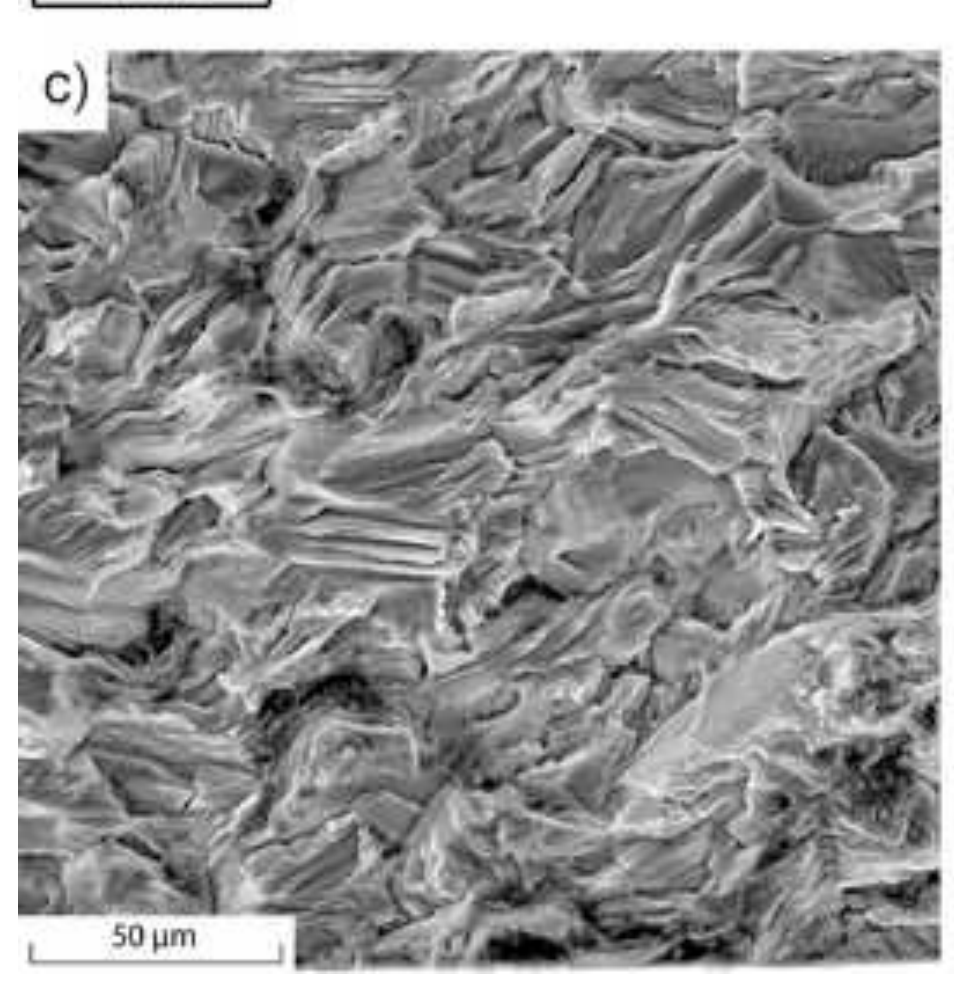

b)
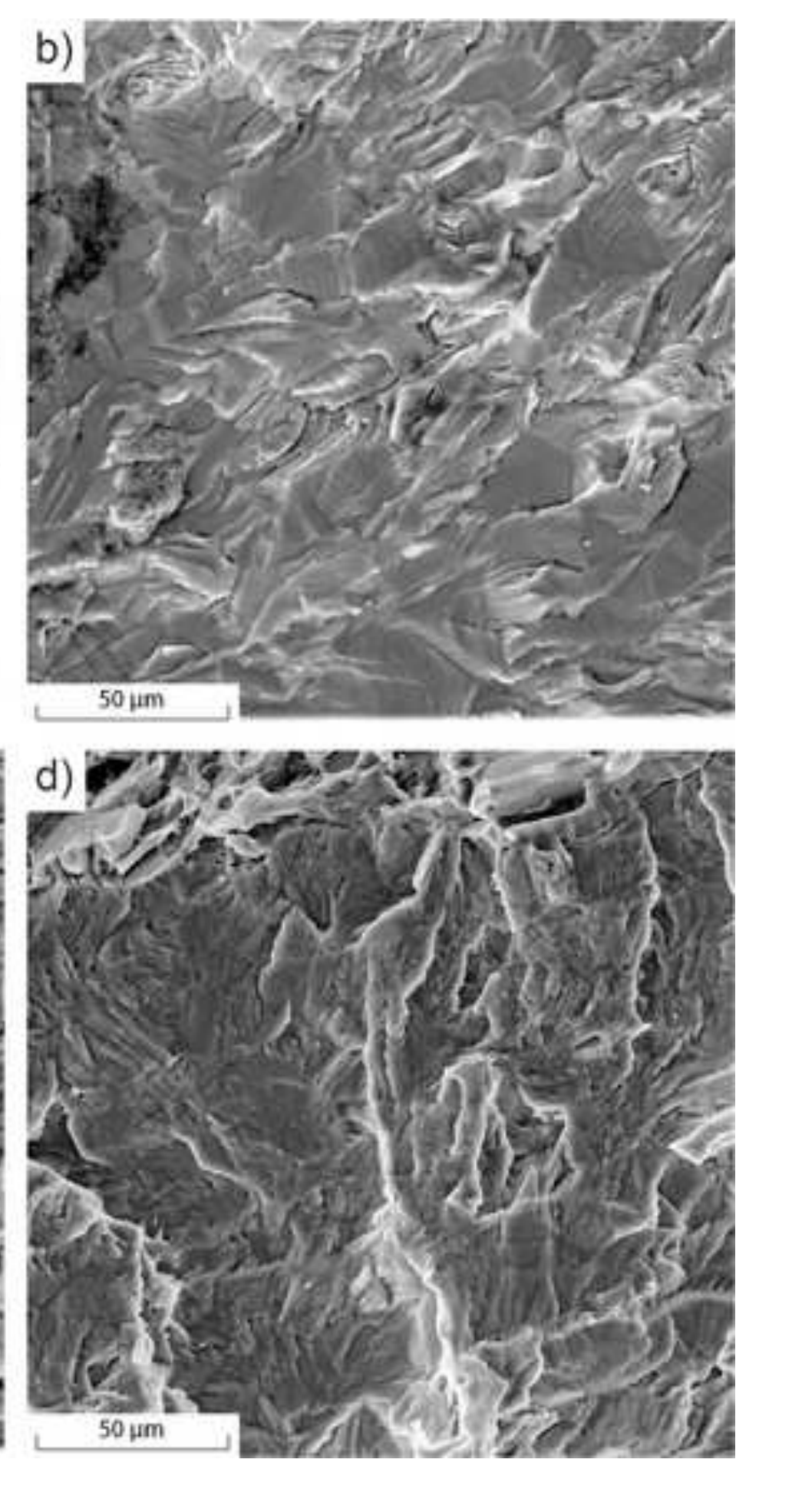
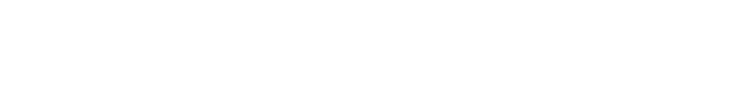

\section{Figure $15-1.5$ Column}

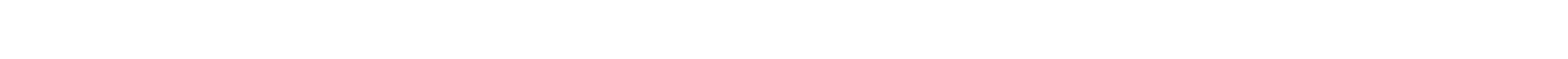

.




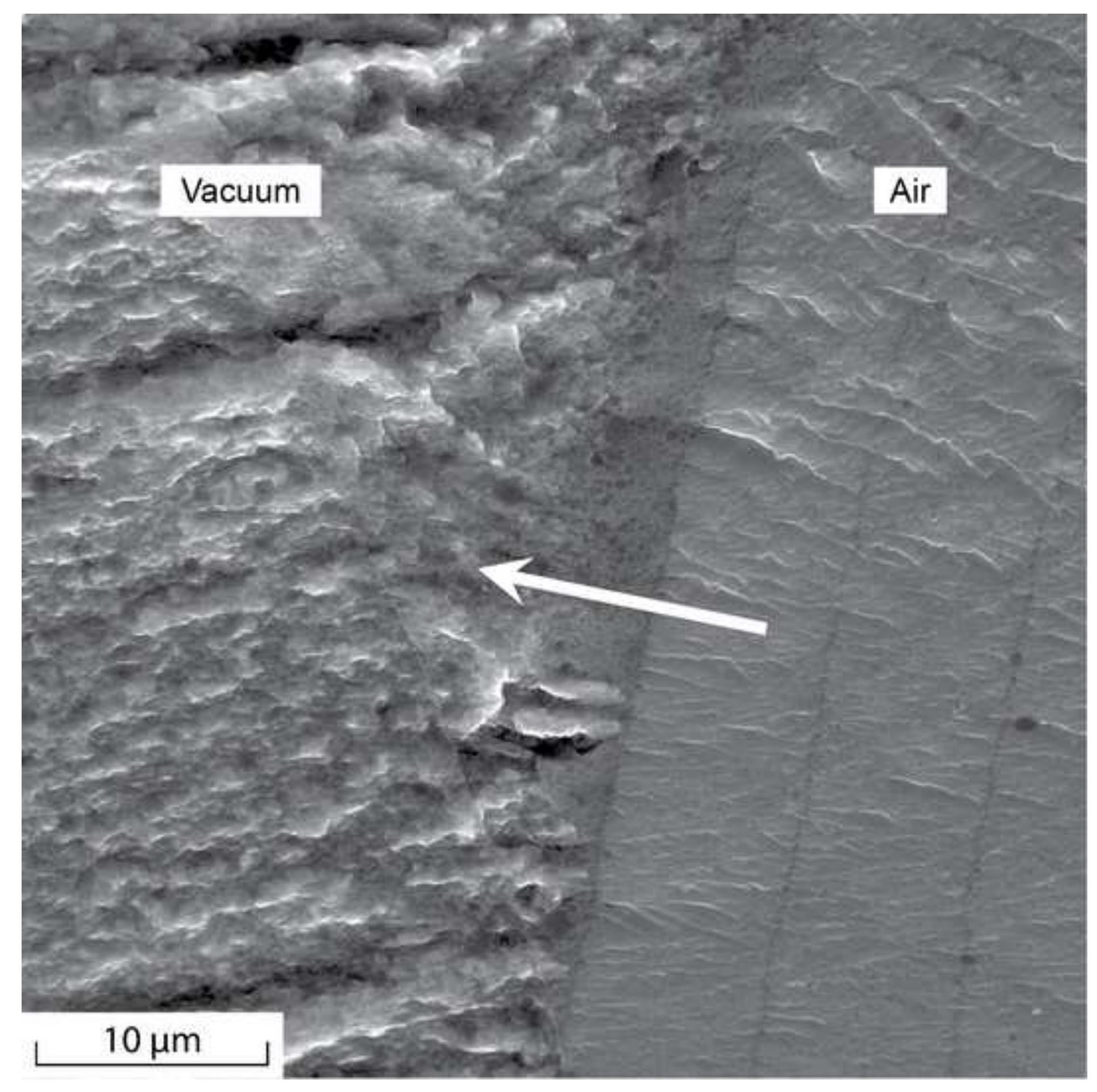


a)

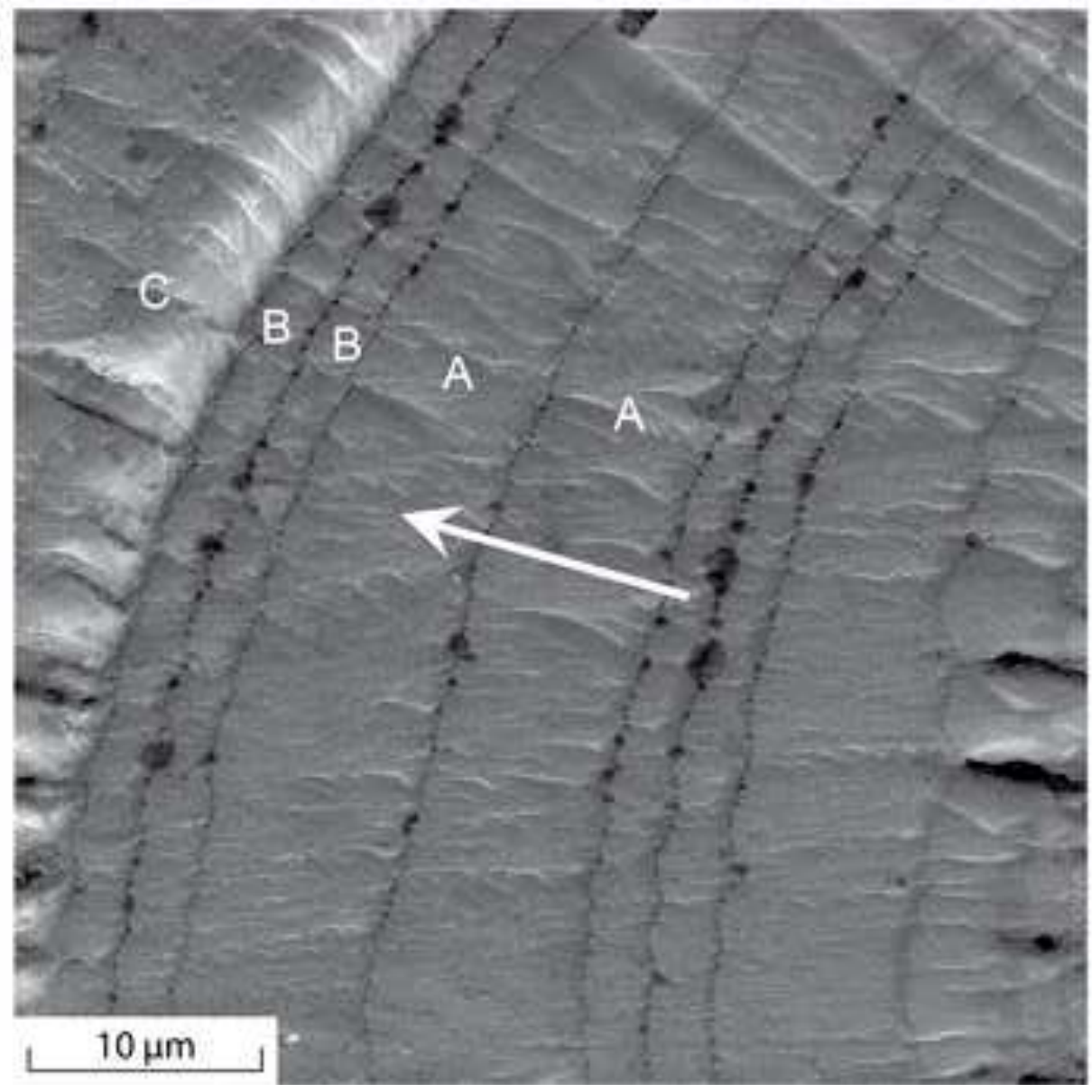

b)

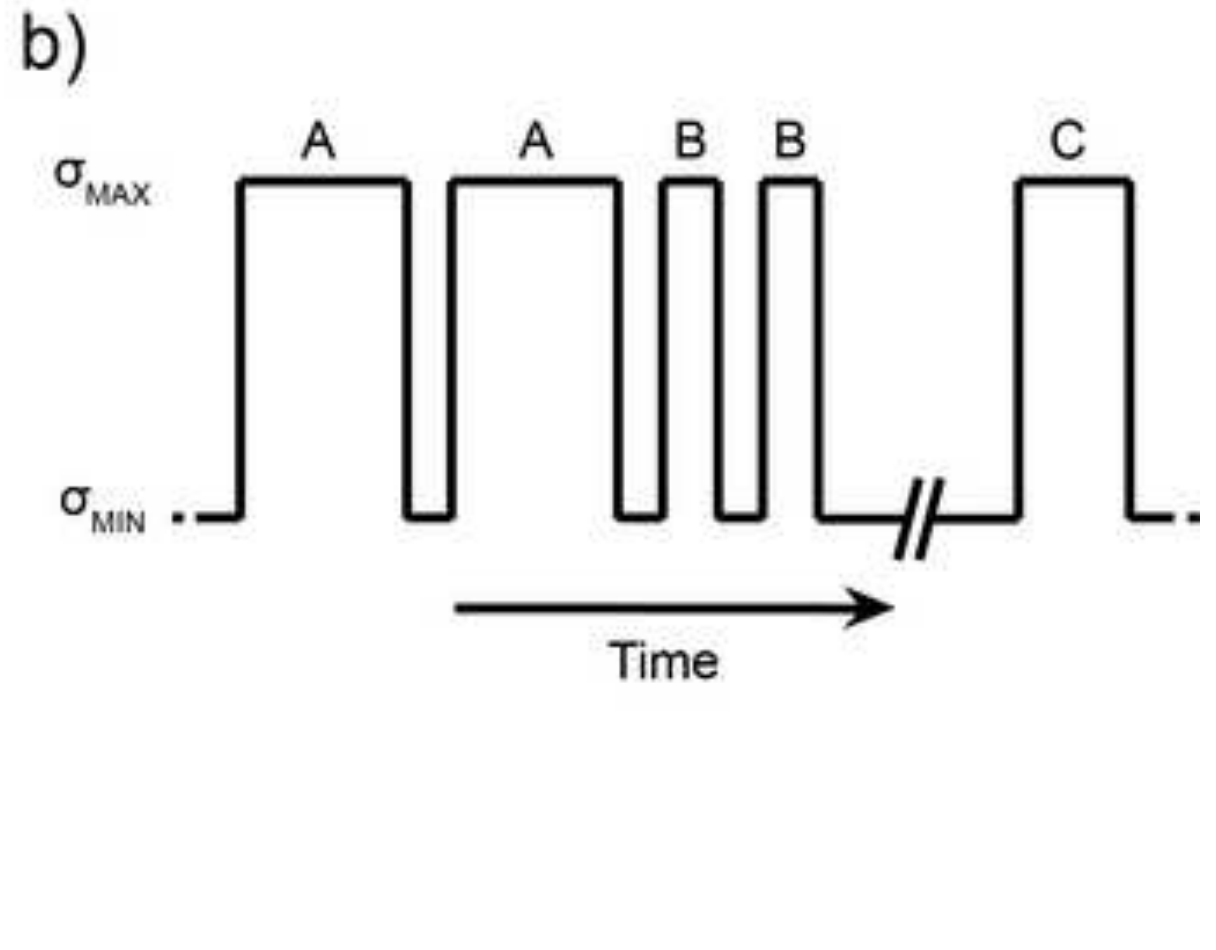




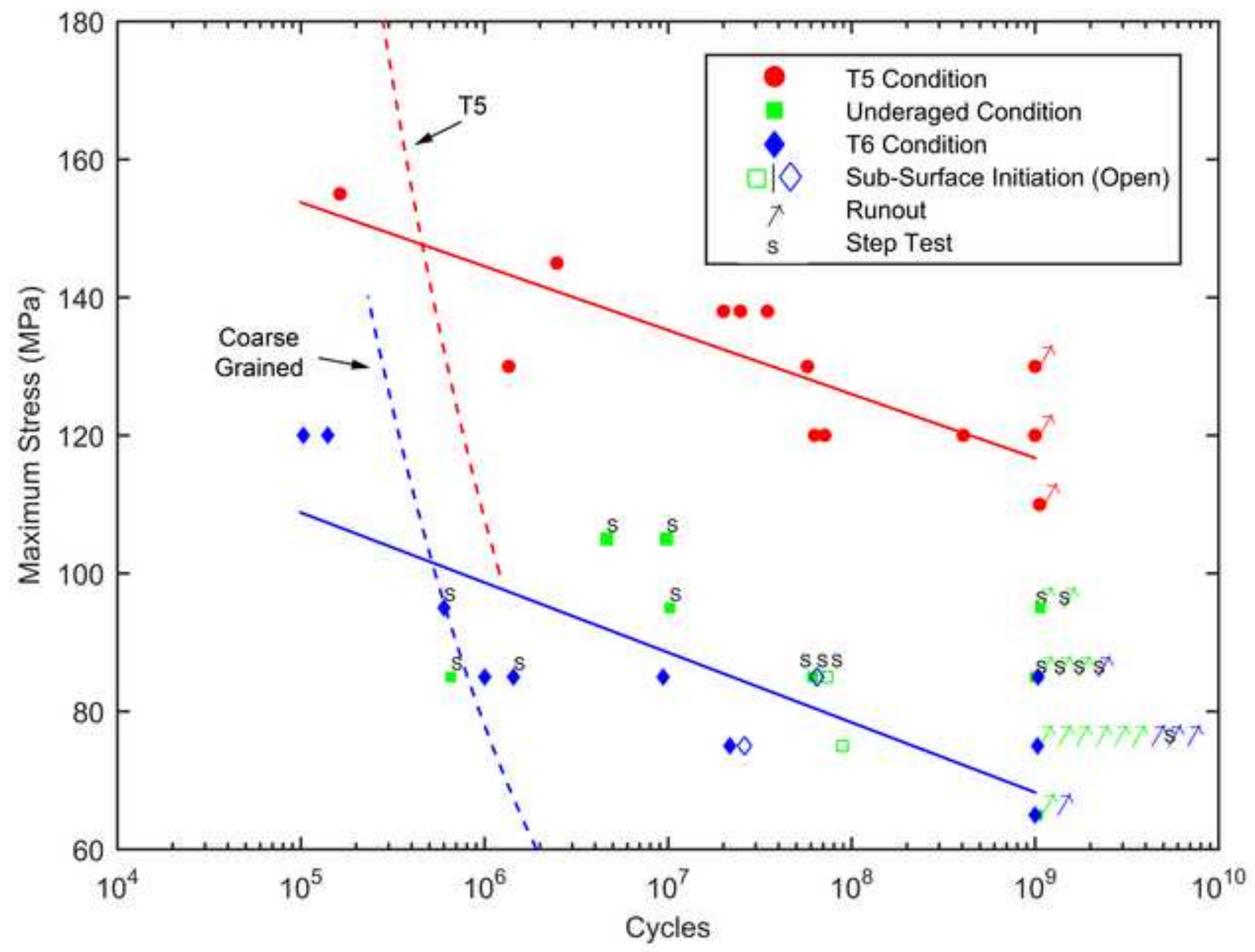

